\title{
Learning from Biosilica: Nanostructured Silicas and Their Coatings on Substrates by Programmable Approaches
}

\author{
Ren-Hua Jin ${ }^{1,2}$ and Jian-Jun Yuan ${ }^{1}$ \\ ${ }_{1}^{1}$ Synthetic Chemistry Lab., Kawamura Institute of Chemical Research \\ 2.ST-CREST \\ ctapan
}

\section{Introduction}

Silica-based materials are important for a wide range of technological applications, such as catalysts, polymeric fillers, coatings, chemical and biological separations, sensors, photonic and electronic devices, bio-encapsulation, enzyme immobilization, bioimaging, drug delivery, and so on (Davis, 2002). Recently, silica synthesis with the control of nanostructures and surface chemistry has been demonstrated to be important to improve the performance for various applications. For example, self-assembled surfactants have been used as templates for the controlled synthesis of mesoporous silicas (Kresge et al., 1992). Fibrous or tubular silicas could be synthesized by templating organogelators (van Bommel et al., 2003). However, these silica productions often involve hash and environmentally unfriendly conditions, such as high or low $\mathrm{pH}$, high temperature and/or pressure, long reaction time, use of toxic and/or expensive organic solvents, as well as multiple steps and complex protocols. Moreover, precise control over the silica nanostructure and morphology still remains a major technical challenge, despite recent advances (Yang et al., 1997).

In contrast, silica biomineralization occurs in water under ambient conditions for various biological systems such as diatoms and sponges, producing exquisite hierarchical structures and multiple morphologies with precise nanoscale control (Schröder et al., 2008; Hildebrand, 2008). Marine organisms produce more than 6 gigatonnes of silicon each year to build their silica skeletons (Tréguer et al., 1995). As a typical example, diatom is eukaryotic single-celled algae with cell walls of being intricately and ornately shaped on the nanometer scale. Such cell wall structure is species-specific, indicating the molecular control of intracellular processes by which organics direct mineral formation (Kröger \& Poulsen, 2008). The architecture and organic-silica composite nature of diatom wall exhibit remarkable mechanic strength and serve as protector armor against phytoplankton predators (Smetacek, 1999). The diatom is important for the biological cycling of both silicon and carbon, with about $20 \%$ of total photosynthetic $\mathrm{CO}_{2}$ fixation. This is equivalent to the photosynthetic activity of all rainforests combined (Field et al., 1998). The recent studies on diatom wall also indicate that $(i)$ the cell wall of Thalassiosira weisflogii acts as a proton buffer for improving the $\mathrm{CO}_{2}$ acquisition via an extracellular carbonic anhydrase (Milligan \& Morel, 2002), and (ii) the square lattice of hole pattern in the girdle band region of the cell wall of Coscinodiscus 
granii acts as a photonic crystal, which may aid in light harvesting for photosynthesis (Fuhrmann et al., 2004).

In this article, we will first give a brief introduction to the biosilica formation with an emphasis on the role of self-assembled organic matrix (i.e. polyamines) for the formation of complex nanostructure and precise nanopattern of biosilicas. The second section provides a comprehensive overview of our recent work on the multiple morphogenesis of silicas by programmable self-assembly of linear polyethyleneimine (PEI). Finally, we will briefly discuss some researches currently under progress and the potential technological applications of our biomimetic PEI-directed silica nanomaterials.

\section{Biosilica formation mediated with self-assembled organic matrix}

Biological organisms are able to take up silicon from the environment in soluble form as silicic acid, store it in cell and catalyze its polymerization into silica with precise structure architecture down to nanoscale (Hildebrand, 2008). Among these processes, self-assembled organic matrix has been assumed to play key roles for directing the biosilicification in diatoms, sponges and higher plants (Perry \& Keeling-Tucker, 2000; Schröder et al., 2008). Sponges synthesize silica in specifically differentiated cells to form a skeletal element (or spicule). Each spicule contains a central macroscopic organic core, or axial filament of protein, that is wholly included within the biosilica (Weaver \& Morse, 2003). By demineralizing the surrounding silica with a buffered hydrofluoric acid solution, the axial protein filaments occluded within the spicules can be isolated. Morse and co-workers discovered that this axial filament consists predominantly of a cathepsin L-ralated enzyme, and termed silicatein (Shimizu et al., 1998; Cha et al., 1999; Weaver \& Morse, 2003; Brutchey $\&$ Morse, 2008). The native silicatein isolated from axial filaments as well as recombinant protein demonstrate the activity for forming silica from soluble silicon alkoxide precursor in solution (Shimizu et al., 1998; Cha et al., 1999). Also the studies using biocatalytically active recombinant silicatein showed that silica formation in sponges is an enzymatic process (Krasko et al., 2000; Schröder et al., 2006). Furthermore, recent studies confirmed the mechanism of self-assembly of silicatein monomers to oligomers and long protein filaments (Croce et al., 2004; Murr \& Morse, 2005; Croce et al., 2007). The results from SAXS examination indicated that the axial filament is formed from a very high degree of organization (hexagonal) of the protein units (Croce et al., 2004; 2007). Müller and coworkers found that silicatein is present not only in the axial filament but also on the surface of the spicules (Müller et al., 2006), supporting the view that growth of spicules occurs through apposition of lamellar silica layer with a distance of 0.2-0.5 $\mu \mathrm{m}$ from each other (Müller et al., 2005).

Diatom cell wall is constructed in a petri-dish-like fashion with a top half overlapping the slightly smaller bottom half. Silica mineralization takes place inside the diatom protoplast within a specialized membrane-bound compartment termed silica deposition vesicle (SDV) (Sumper \& Kröger, 2004). Biosilicas from all diatom species investigated so far has turned out to be a composite material composed of silica, proteins and long-chain polyamines (Sumper \& Kröger, 2004; Kröger \& Poulsen, 2008). Three families of proteins have been identified in the cell wall of marine diatom $C$. fusiformis, termed frustulins, pleuralins and silaffins (Pohnert, 2002). Frustulins are a group of calcium-binding glycoproteins being assumed to play a role in cell adhesion to surfaces, gliding of pennate diatoms, and protection against desiccation (Kröger et al., 1994; 1996). The pleuralins (HF-extractable 
proteins) are highly acidic molecules, comprising a proline-rich region and several repeats of a proline-, serine-, cysteine, aspartate-rich domain (Kröger et al., 1997). Immunoelectron microscopy studies revealed that frustulins and pleuralins are not involved in silica formation because they become associated with the biosilica only after its deposition on the cell surface (van de Poll et al., 1999; Kröger \& Wetherbee, 2000). Silaffins (proteins with silica affinity) are a group of low molecular polypeptides, which can be extracted from the diatom cell wall using anhydrous HF (Kröger et al., 2002). Silaffins were found to be mainly composed of serine and lysine residues. Using a milder extraction condition (a slightly acidic, aqueous ammonium fluoride solution), native silaffins (termed natSil, Figure 1A) have been isolated from $C$. fusiformis. (Kröger et al., 2002). In the native silaffins, all the serine units are found to be phosphorylated, and all the lysine units are either methylated or covalently linked with a long-chain polyamine (Kröger et al., 1999; 2001; 2002). Silaffin NatSil-1A is extremely active in promoting silica precipitation in vitro, causing silica

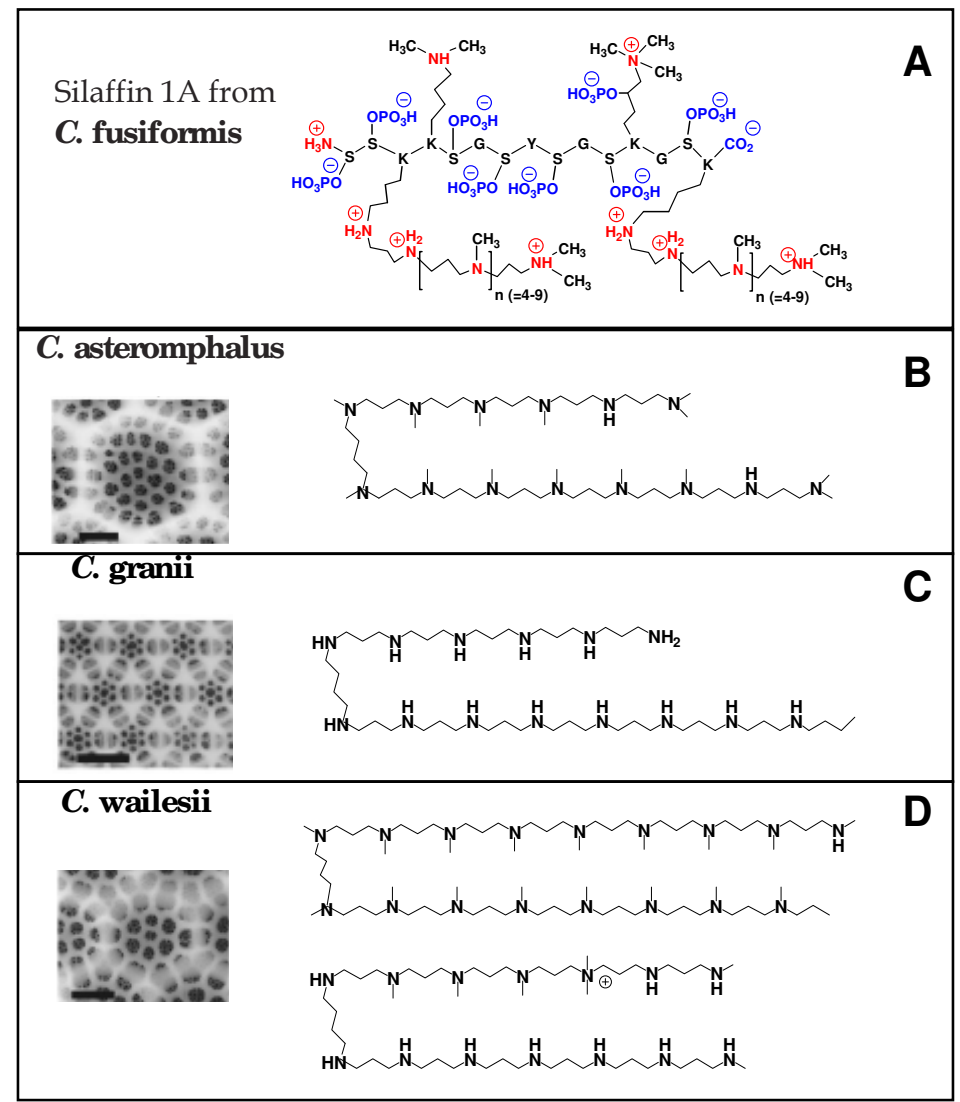

Fig. 1. Diatoms and their organic components active for silica deposition and pattern formation. (A) chemical structure of native silaffin- 1 of $C$. fusiformis. (B), (C) and (D) SEM images and polyamines isolated from the differently pattered cell walls of diatoms $C$. asteromphalus, $C$. granii and $C$. wailesii, respectively. The bars: $1 \mu \mathrm{m}(\mathrm{B}-\mathrm{D})$. 
precipitation within a few minutes by accelerating polycondensation of silicic acid and acting as a flocculating agent (Kröger et al., 2002; Poulsen et al., 2003). The supermolecular aggregates self-assembled from Silaffin-1 A in solution were estimated to comprise 700 peptide molecules, which appears to serve as a template for silicic acid polycondensation (Brunner et al., 2004).

Long chain polyamines (LCPA) were found to be characteristic constituent of biosilica from all genera of diatoms analyzed so far (Sumper \& Kröger, 2004). The cell wall silica from most diatom species studied to date has a roughly equivalent content of silaffins and LCPA. The studies also showed that some of diatoms, C. asteromphalus, C. granii, and C. wailesii, appear to contain only LCPA (Sumper, 2002). In biosilicas, LCPA could exist in peptide-bound or peptide-free state. In diatom $C$. fusiformis polyamines with about 5-10 N-methylpropylamine units are attached to lysine residues of Silaffin NatSil-1A (Figure 1A). The attached polyamines are important for imparting the zwitterionic structures to NatSil due to their cationic property, which has been proposed to be an essential prerequisite for silica biomineralization. Furthermore, as the active functional groups on the silaffins appear to be the LCPA, polyamines alone can also promote silica formation in a similar way to silaffins in the presence of inorganic phosphate or other polyvalent anions (Kröger et al., 2000).

Recently, Sumper and co-workers have revealed that the polyamines from different diatom species exhibit different molecular structure, indicating that polyamines are species-specific for creating species-specific silica nanostructures (Sumper \& Lehmann, 2006). Structural variations of polyamines include the overall chain length, the degree of methylation, the positions of secondary and tertiary amino functionalities and the site-specific incorporation of quaternary ammonium functionalities. A selection of typical polyamine structures covering these features and their corresponding silica nanopattern are shown in Figure 1B, $\mathrm{C}$ and $\mathrm{D}$. Moreover, polyamines have also been proposed to play key roles for nanopattern formation of diatoms. By examining the silica formation guided by self-assembled emulsion droplets from polyamine-phosphate system, Sumper found that hexagonal network silica was produced by using polyamine-stabilized silica sol as the silicon source (Sumper, 2004). In contrast, silica nanoparticles were obtained if silicic acid was used as source. Polyamines are likely to not only stabilize silica sols but also induce a phase-separation, producing (hexagonal) pattern silica. Thus, both the supramolecular self-assembly and the presence of polyamines are important to control both the rate and mechanism of silica precipitation and formation of the elaborate patterns.

\section{Multiple morphogenesis of silicas from programmable self-assembly of linear PEls}

\subsection{Linear PEls, crystallization and crystalline morphology}

PEI can be divided into branched and linear PEIs according to their chain architecture. Commercial branched PEIs are obtained by cationic ring-opening polymerization of aziridine (ethylene imine) in water or water-alcohol mixture with a protonic acid as catalyst. The branched PEI is a polyamine containing primary, secondary and tertiary amine groups, which has a high cationic charge density in water and a branched structure. The branched PEIs have been widely used in many industrial fields, such as water treatment flocculants, paper production, dye fixation in textile processing, pigment dispersant, coatings, pressure sensitive adhesives, and so on. Recent studies have demonstrated the applications of branched PEI in medicinal chemistry, for example as most efficient nonviral vectors for gene 
delivery. In contrast, linear PEIs obtained from the hydrolysis of linear polyoxazoline in acidic and basic conditions (Saegusa et al., 1975; Jin \& Motoyoshi, 1999), are highly crystalline owing to its linear structure. Different to the branched one, linear PEI is composed of only secondary amine. Linear PEI is difficult to dissolve into water and normal organic solvents (except methanol) at room temperature due to the crystalline structure (Yuan \& Jin, 2005a). We have been able to design linear PEI backbone into various chain architectures (Figure 2). About two decades ago, Chatani and co-workers did the pioneering works on the understanding of crystalline structure of linear PEI (Chatani, et al., 1981; 1982; 1983). Depending on the humid atmosphere, four crystalline phases consisting of anhydrate, hemihydrate, sesquihydrate, and dihydrate per EI unit have been confirmed. Linear PEI chains adopt a double-stranded helical conformation by forming parallel array in the anhydrate, while all-trans planar-zigzag conformations are adopted by the fully extended form for the hemihydrate, sesquihydrate, and dehydrate. Recently, the crystalline structure and the phase transition of the linear PEI were further studied by Hashida et al (Hashida et al., 2002) and Hasegawa et al (Kakuda et al., 2009), mainly based on the new-developed spectroscopy methods. Compared to the wide applications of branched PEI in industrial and academical research fields, linear PEI seems to be only used in the laboratory in a very limited field. Recently, linear PEIs have been attempted to be used for gene delivery (Hsiue et al., 2006), biosensors based on ferrocene modification (Merchant et al., 2009) and electrochemically responsive thin film (Schmidt et al., 2009), mainly based on the long-chain secondary amine property. In contrast, the nature and characteristics of crystalline structure of linear PEI have not been exploited for materials application, due to that the selfassembled information programmed in the crystalline structure of linear PEI has not been discovered until our recent findings (Yuan \& Jin, 2005a). Our interest in linear PEI started from our studies on the synthesis, micelle/vesicle/ emulsion self-assembly and silica-based hybrid materials of chain-architecture-controlled polyoxazolines (Jin, 2002a; 2002b; 2003a; 2003b; 2003c; 2004). For example, star architecture consisting of a small benzene core and densely-six-armed poly(methyloxazoline) has been observed to be able to self-assemble in situ into a superstructured colloidal crystalline polymer in the reaction solution (Jin, 2003b). The hydrophobic-hydrophilic amphiphilic star block copolyoxazolines have been designed to control porphyrin moieties in the different sites of self-assembled micelles (Jin, 2002a). By hydrolyzing one of block from star block polyoxazoline into polyethyleneimine, we can produce micelles with porphyrin core and cationic shell in water and reverse micelles with cationic core and porphyrin-funcationalized shell in organic media (Jin, 2003c).

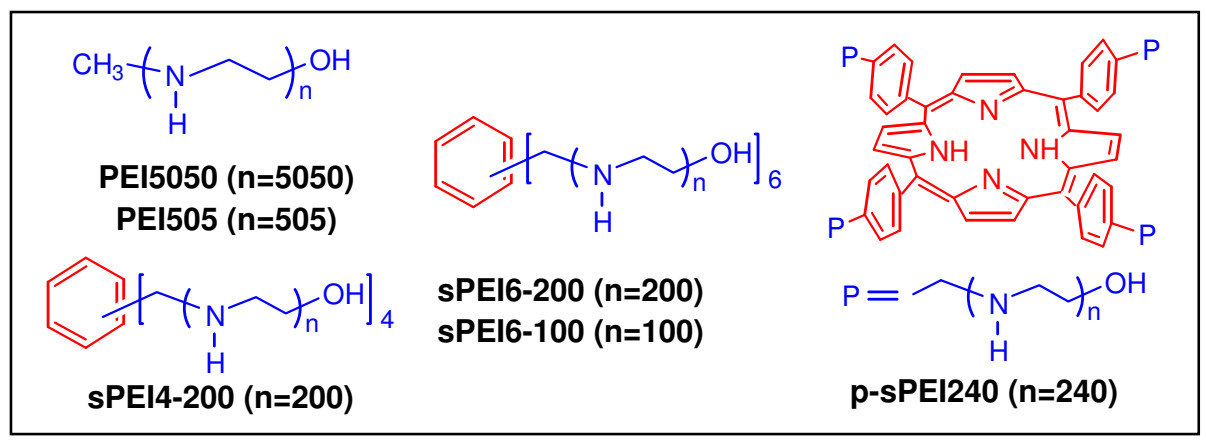

Fig. 2. Linear PEIs with various chain architectures. 


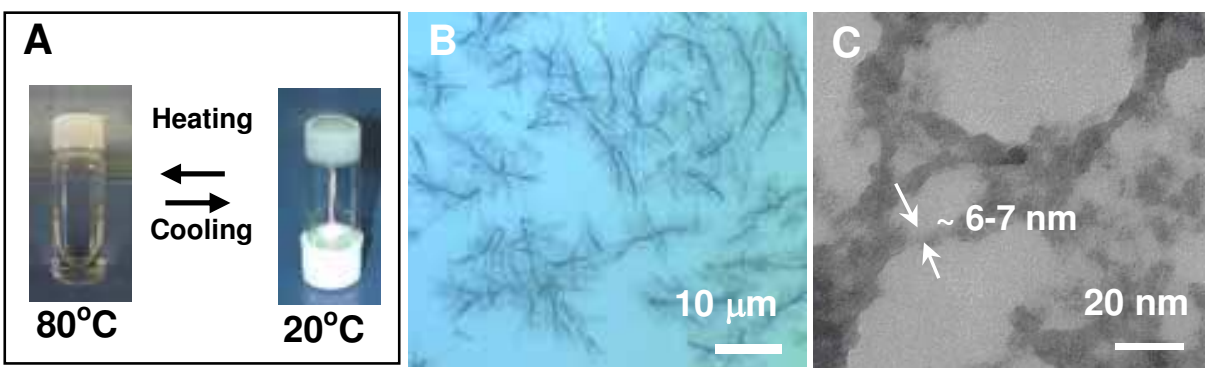

Fig. 3. Fibrils self-assembled from linear PEI in water. (A) Reversible hydrogelation of PEI5050 with $1 \mathrm{wt} \%$ concentration in water by heating-cooling cycles. (B) Optical microscope image of branched fibrous bundles of crystalline PEI5050 in water (1 wt\%). (C) TEM image of fibrous aggregates of $0.25 \mathrm{wt} \%$ PEI5050 in water.

The breakthrough of the linear PEI-directed inorganic materials synthesis came from the discovery of crystalline morphology of linear PEI in water media (Yuan \& Jin, 2005a). We found that linear PEI do not dissolve in water at room temperature, but is highly soluble upon heating at $80{ }^{\circ} \mathrm{C}$ (Figure $3 \mathrm{~A}$ ). It is interesting that the hydrogelation occurred upon naturally cooling the hot aqueous solutions of PEI to room temperature, and such hydrogelation is completely reversible by heating-cooling cycles (Figure 3A). The XRD studies on the $5 \mathrm{wt} \%$ PEI5050 hydrogel indicated the diffraction patterns at $2 \theta$ of 13.5, 20.3, 27.2 and $27.9^{\circ}$ due to the dihydrate crystalline structures of PEI. This is consistent to the earlier studies from Chantani et al (Chatani et al., 1983). This novel thermoreversible hydrogel from linear PEI shows the tunable gel-sol transition temperatures from about 43 to $79^{\circ} \mathrm{C}$, depending on the PEI concentrations and solution conditions. Linear PEI could gelate neat water with a concentration as low as about $0.25 \mathrm{wt} \%$, indicating that one EI unit could gelate 956 water molecules. Such high ability to gelate water is unusual for physical hydrogel from normal polymers. Thus we assumed that the self-assembled nanostructure from linear PEI should play vital role for strongly gelate water molecules. Microscopy studies supported this assumption. Direct observation by optical microscopy on a small piece of PEI5050 hydrogel with 1.0 wt. \% concentration revealed that the aggregates are composed of fibrous bundles on the micrometer scale (Figure 3B). It seems likely that many crystalline unit nanofibers organized into the branched bundles. TEM studies indicated that the unit nanofibers were about 6-7 nm in width (Figure 3C). Our further experiments confirmed that star-like PEIs with linear backbones could also gelate water in the similar way as that of linear PEI (PEI5050) by forming fibrous crystalline structure; in contrast, the branched PEI just forms molecularly dissolved solution under similar conditions. This result indicated that linear backbone is prerequisite conditions in the formation of PEI fibrous crystalline structures. This physical and ice-cream-like hydrogel could be chemically crosslinked by glutaraldehyde to improve the mechanical properties. This is the first finding of fiber-like crystalline morphology for linear PEI in water-based media upon naturally cooling a hot solution. There have been a number of studies on the modification of linear PEI by attached the hydrophobic or hydrophilic blocks (Akiyama et al., 2000), but the crystalline morphology studies are extremely rare. Recently, Menzel and co-workers reported the thermal gelation of amphiphilic PEI with end-capped by alkyl chains (alky-PEI), and cryoSEM observation revealed the fibrous network structure of the alkyl-PEI crystalline hydrogels (Navarro et al., 2009). This is consistent with our earlier results. 


\subsection{PEI nanofiber-templated silica deposition}

Marine sponges produce structured spicule by templating self-organized organic fibers, which simultaneously serve as template, scaffold and catalyst for silica mineralization. Inspired by this silica formation in nature, we explored to use our self-assembled crystalline PEI nanofiber as biomimetic template for silica deposition (Jin \& Yuan, 2005a; Yuan \& Jin, 2005b; Yuan et al. 2006) (Figure 4A). The silica deposition was simply achieved by mixing an aqueous dispersion of PEI5050 nanofiber, ethanol and TMOS at $20^{\circ} \mathrm{C}$ for $40 \mathrm{~min}$. TEM observation clearly demonstrated the formation of PEI@silica nanofibers with a width of about 20-23 nm (Figure 4B). This hybrid nanofiber has well-defined core-shell structure composed of an axial, crystalline PEI filament core of about 5-7 $\mathrm{nm}$ in diameter and a silicified shell of about $7 \mathrm{~nm}$. Silica tube could be obtained by calcining the PEI@silica hybrid nanofiber at $500^{\circ} \mathrm{C}$ to remove the organic components (Figure $4 \mathrm{C}$ ). The representative samples of PEI@silica nanofibers and silica nanotubes after calcination at $700^{\circ} \mathrm{C}$ showed BET surface area of about 71 and $298 \mathrm{~m}^{2} / \mathrm{g}$, respectively, indicating that removal of organic PEI (i.e., nanotube formation) contributes greatly to the increase in surface area. We also found that silica deposition templated by this unique PEI nanofiber could occur at a significantly fast rate. Elemental analysis on the PEI@silica sample from 10 min silica deposition showed $74 \mathrm{wt} \%$ silica content.
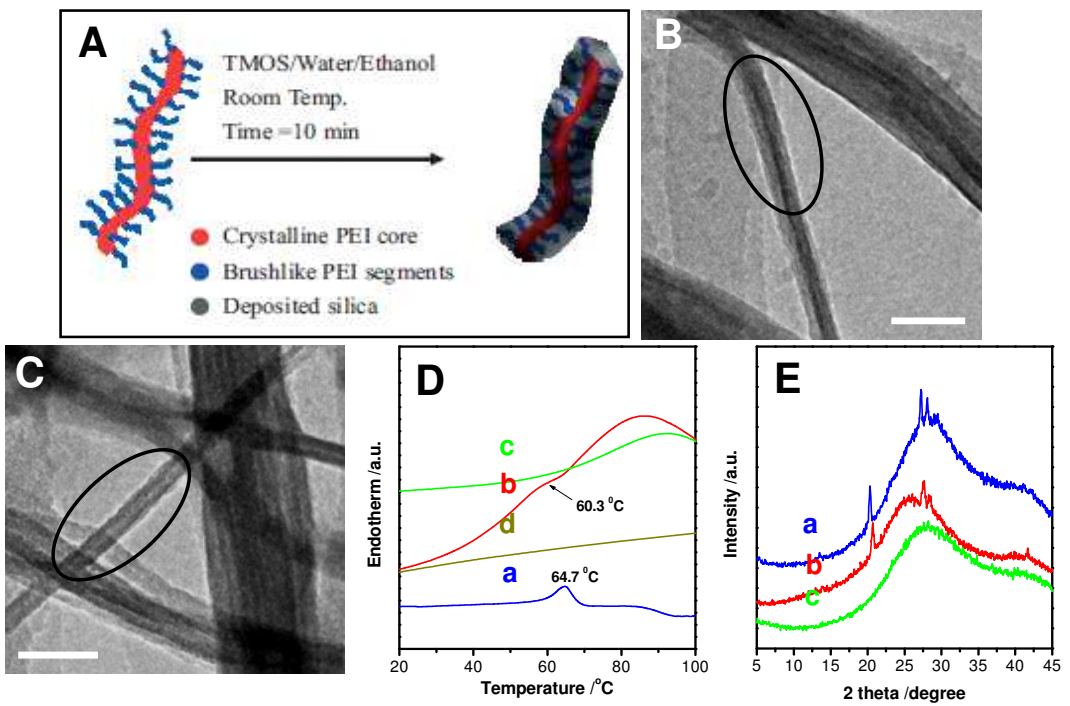

Fig. 4. Silica mineralization by templating self-assembling PEI nanofiber. (A) Schematic representation of PEI nanofiber serving as biomimetic template for controlled silica deposition. (B) TEM image of unit PEI@silica nanofiber prepared by using aggregates of 2 wt $\% \mathbf{P 5 0 5 0}$ as template and TMOS as silica source. (C) TEM image of silica nanotube obtained by calcining (B) at $500^{\circ} \mathrm{C}$. The bars are $50 \mathrm{~nm}$ for B and C. (D) DSC traces of PEI5050 under different environments: (a) aqueous aggregate of $2 \mathrm{wt} \%$ PEI5050, (b) PEI@silica composite, (c) PEI@silica composite after ethanol washing, (d) the second heating run of (b). (E) XRD patterns of (a) aqueous aggregate of 2 wt\% PEI5050, (b) PEI@silica composite and (c) PEI@silica composite after ethanol washing. 
No nontemplated silica formation was observed, indicating that the silica deposition proceeds exclusively and site selectively on the surface of fibrous PEI aggregates. Selforganized PEI nanofiber with a crystalline core serves as a template for shape direction, and the amorphous shell with brushlike PEI segments acts as the catalyst/scaffold for silica deposition at ambient conditions. This mechanism has been confirmed by the combined studies of ${ }^{1} \mathrm{H}$ NMR, XRD and DSC. ${ }^{1} \mathrm{H}$ NMR study on a dilute dispersion of PEI nanofibers in $\mathrm{D}_{2} \mathrm{O}$ confirmed the existence of brushlike PEI shell on the surface of crystalline PEI core. DSC measurements demonstrated a melting peak at $60.0^{\circ} \mathrm{C}$ for crystalline PEI in PEI@silica hybrid nanofiber, which is similar to that before silica deposition (Figure 4D). In addition, the same diffraction peaks $(2 \theta)$ at $20^{\circ}, 27^{\circ}$, and $28^{\circ}$, ascribed to a dihydrated PEI crystal $\left(\mathrm{NCH}_{2} \mathrm{CH}_{2} / \mathrm{H}_{2} \mathrm{O}=1: 2\right)$ with a zigzag conformation, were obtained by XRD measurement on samples before and after silica deposition (Figure 4E). Both DSC and XRD investigation confirm the template role of crystalline PEI nanofiber upon silica deposition.

To design model systems for mimicking silica biomineralization, Menzel and co-workers (Menzel et al. 2003) reported using linear PEI with a degree of polymerization of 8-9 for silica deposition. This low-molecular-weight linear PEI was dissolved into $10^{-5} \mathrm{M} \mathrm{HCl}$ solution and the silicification was performed at $\mathrm{pH} 4.3$. This experiment confirmed the strong accelerating effect for silicification of linear PEI as a molecular polyamine. However, no characteristic morphogenesis was addressed under the silica deposition conditions investigated, since self-assembled crystalline nanofiber morphology of linear PEI, which could be transcribed into silica, is not available at pH4.3. Recently, Patel et al (Patel et al., 2009) reported silica formation onto nanofibers of linear PEI blended with poly(vinyl pyrrolidone) obtained via electrospinning. Schiraldi and co-workers (Johnson et al., 2009) described the production of linear PEI/clay aerogel and the subsequent mineralization of this composite by condensation of tetramethyl orthosilicate (TMOS). In both cases of PEImediated silica mineralization depending on electrospinning fibers and aerogel, however, the characteristic nanostructures due to the PEI crystalline property have not been exploited. Our processing for shaped silicas is remarkably different from conventional silica-fiber formation based on the fibrous aggregates from small-molecule gelators (van Bommel et al., 2003), in which a solution deposition of silica (nontemplated silica) is normally unavoidable because an acidic or basic catalyst is present in solution. Later, a surface mechanism was proposed for silica deposition by designing an organogelator possessing a gelating cholesterol moiety and a catalytic benzylamine residue (van Bommel \& Shinkai, 2002), with the silica formation occurring merely on the gel-fiber surface. However, the silicification was performed in organic media, and seems to be relatively low in efficiency, because a long deposition time ( 1 week) and heat treatment are needed. Recently, Shimizu and co-workers demonstrated direct silica deposition without the aid of solution catalysis by using tubular fibers consisting of peptidic lipids with secondary ammonium hydrochloride residues on the surface of the tubular assemblies (Ji et al., 2004). This approach can produce hollow silica cylinders with very thin walls $(4.5-8.0 \mathrm{~nm})$ but still requires a longer deposition time (1 week). The organogelators and lipids used for such silica formation are costly, thus restricting their widespread adoption. Also, organogelator-derived silicas generally lack the possibility of multiple morphogenesis and hierarchical architecture of silicas because of the small molecular size of the gelators.

Compared to organic alkoxysilane, using sodium silicate as silica source is cost-effective and environmentally benign. Such an inorganic silica source does not produce organic byproducts. By using self-assembled PEI nanofiber as structure directing templates, we have 
successfully achieved fibrous PEI@silica hybrid structures by using commercial water glass as source (Figure 5). The nanostructure and morphologies could be controlled by adjusting polymer concentrations and $\mathrm{pH}$ values of the aqueous solution of sodium silicate (Zhu \& Jin, 2008).
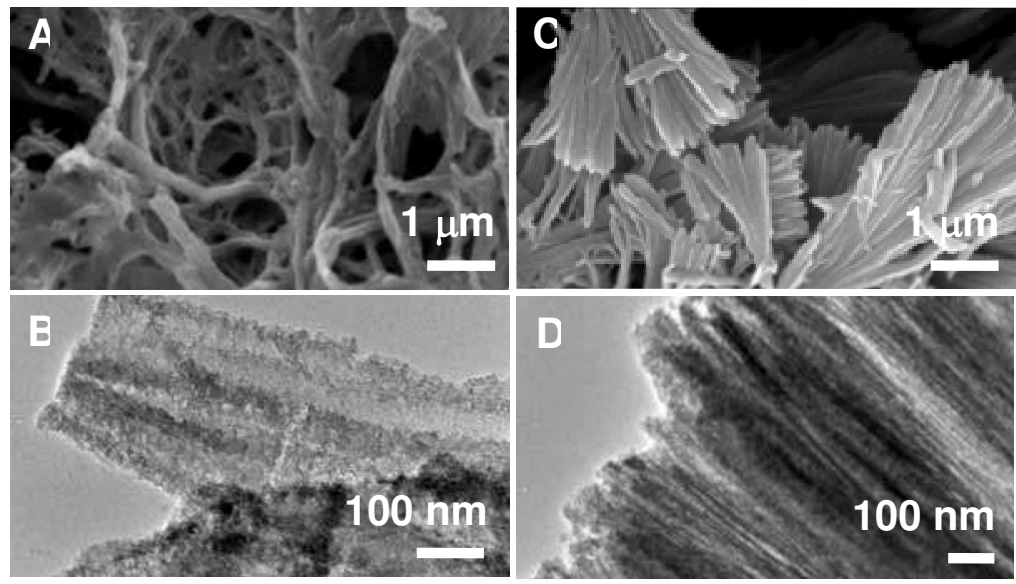

Fig. 5. Fibrous PEI@silicas synthesized by using water glass as source. (A) SEM and (B) TEM images of PEI@silica formed by the mediation of $1 \mathrm{wt} \%$ of PEI5050; (C) SEM and (D) TEM images of PEI@silica obtained by the mediation of sPEI6-200.

\subsection{Morphological control of silicas by adjusting the self-assembly of linear PEI}

Different to the conventional biomimetic silicification systems based on molecular selfassembly (Cha et al., 2000; Patwardhan et al., 2005; Pouget et al., 2007; Yuan et al., 2007), linear PEI-directed silica formation featured with multiple morphogenesis and wellcontrolled hierarchical architectures through programmed self-assembly of PEI macromolecules with linear backbones. The self-assembly of crystalline PEI aggregates could be controlled by a programmable adjustments of some simple parameters, including polymer chain architecture and molecular weight, concentrations, additives, media, physical field and so on. The programmed PEI aggregates are transcribed into silicas with multiple morpholognesis by performing a biomimetic silicification.

\subsubsection{PEl concentration}

One of extremely simple method for adjusting PEI self-assembly is to change the concentrations of PEI in water (Yuan \& Jin, 2005b). The concentration effect of silica morphogenesis was addressed by performing silicification reaction on the aggregates from PEI505 with concentrations from 5.0 to $0.1 \mathrm{wt} \%$ using TMOS as silica source under room temperature for $40 \mathrm{~min}$ (Figure 6). It was found that silicas produced from PEI505 with concentrations from 2.0-5.0 $\mathrm{wt} \%$ show fiber-based bundles with a size of several micrometers. Obviously, the bundles tend to expand in a two-dimensional way, and became looser when the concentrations of PEI505 decrease. Further decreasing PEI concentration to $\leq 1.0 \mathrm{wt} \%$ leads to morphological transformation of silicas from the fiber bundles into curved leaf-like film. Silicas prepared from PEI505 aggregates of $0.5 \mathrm{wt} \%$ concentration 
show leaf lamellae composed of interwoven nanofibers, meaning that the silica film grew by linking separate fibers to each other (Figure 6). The silica film mediated by $0.25 \mathrm{wt} \%$ PEI505 was thicker and the fiber structure still could be resolved. When PEI505 concentration decreased to $0.1 \mathrm{wt} \%$, the silica film shows a smooth surface without fiber structure. It was assumed that the formation of a thick silica film, which is supported by fiber-to-fiber linking, is associated with the presence of a large amount of PEI chain that are attached to the surface of crystalline PEI aggregates. ${ }^{1} \mathrm{H}$ NMR studies indicated that the relative contents of amorphous brush on the crystalline PEI fibril dramatically increased as the PEI concentrations deceased from 0.3 to $0.05 \mathrm{wt} \%$. This means that PEI aggregates obtained from lower concentrations would favor to offer much more brush sites on crystalline PEI surface, where the promoted silicification reaction led to the formation of silica film structure.

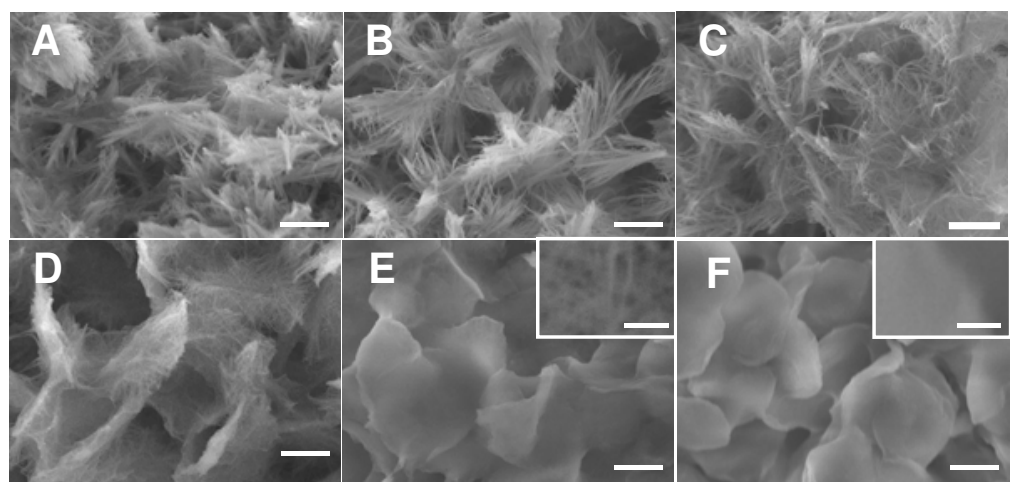

Fig. 6. Morphological dependence of PEI@silicas on the concentrations of PEI505. SEM images of PEI@silicas synthesized by PEI505 aggregates with the concentrations of 5, 3, 2, $0.5,0.25$ and $0.1 \mathrm{wt} \%$ for $(\mathrm{A}),(\mathrm{B}),(\mathrm{C}),(\mathrm{D}),(\mathrm{E})$ and $(\mathrm{F})$, respectively. Bars are $5 \mu \mathrm{m}$ for A-F and $500 \mathrm{~nm}$ for insets of $\mathrm{E}$ and $\mathrm{F}$.

\subsubsection{Polymer architecture}

Multiple morphogenesis of silicas could be generated by designing and using the linear PEI with different chain architectures (Jin \& Yuan, 2005a). As shown in Figure 7A and B, silicas templated by using PEI5050 aggregates with concentrations of 2 and $0.25 \mathrm{wt} \%$ exhibited the expanded bundle and leaf morphologies, respectively. In contrast, a six-armed star PEI with a small benzene core (sPEI6-100) directed the formation of silicas with dramatically different morphologies. A fibrous framework was created by using $2 \mathrm{wt} \%$ sPEI6-100 aggregates as templates (Figure 7C). High-magnification observation reveals that larger fibers are composed of thinner nanofibers. When the concentration of sPEI6-100 decreased to 0.25 $\mathrm{wt} \%$, silicification produced silicas with looser bundle morphologies (Figure 7D). Each silica bundle was observed to be composed of well-defined nanofibers with the length of tens of micrometer and the diameters of about 30-50 nm. Compared to PEI5050 (simple linear architecture), sPEI6-100 (small benzene core with six-arm star architecture) demonstrated the enhanced ability to form self-assembled aggregates and subsequent silicas with welldefined unit nanofiber structure. It is very interesting that the silica asters were achieved by using a star PEI with porphyrin core (p-sPEI4-240). The asters could have more than five silica arms, which expands towards three-dimensional directions (Figure 7E). The arms 
become wider towards the outer of silica asters. Each arm shows serrate end, indicating that the arms are densely organized with unit nanofibers. The silicas obtained from the lower content of p-sPEI4-240 $(0.25 \mathrm{wt} \%)$ still retained the aster morphology.
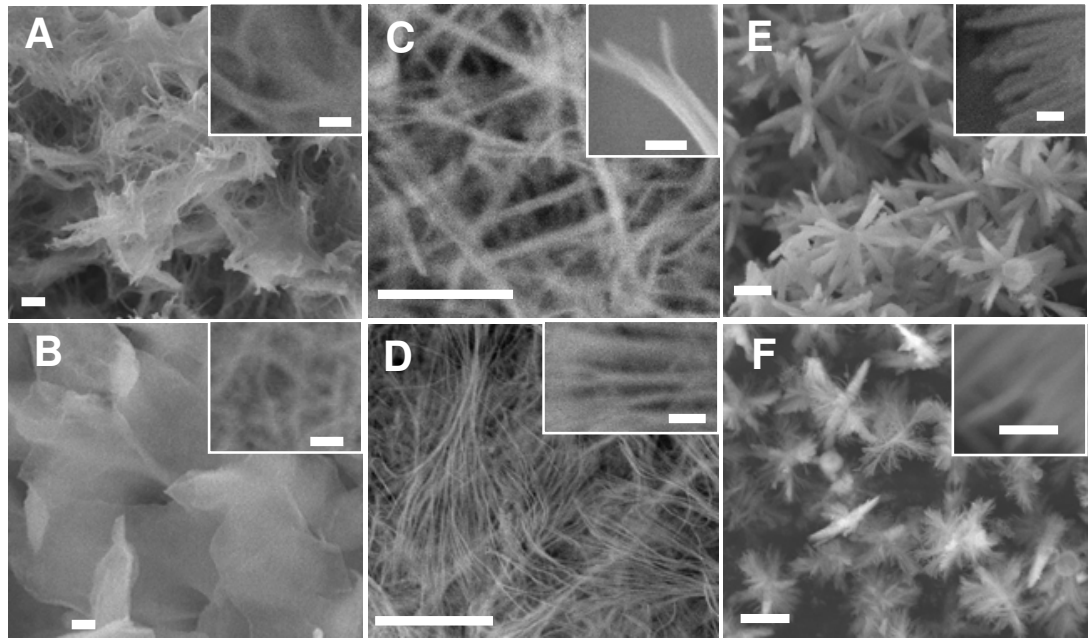

Fig. 7. Shaping silicas by designing linear PEI backbone into star architecture. SEM images of PEI@silicas prepared by using PEI5050 with concentrations of $2.0 \mathrm{wt} \%$ (A) and $0.25 \mathrm{wt} \%$ (B); using sPEI6-100 with concentrations of $2.0 \mathrm{wt} \%$ (C) and $0.25 \mathrm{wt} \%$ (D) and p-sPEI4-240 with concentrations of $2.0 \mathrm{wt} \%$ (E) and $0.25 \mathrm{wt} \%(\mathrm{~F})$. The bars are $2 \mu \mathrm{m}$ for (A-D) and $100 \mathrm{~nm}$ for each inset.

\subsubsection{Media for PEl crystallization}

By taking advantage of methanol being a good solvent for dissolving crystalline PEI at room temperature, we developed the strategy to generate shaped silicas by using methanol as a mediator to adjust the programmed self-assembly of crystalline PEI (Jin \&Yuan, 2005b). This methanol-programmed approach could both enrich the shape generation of silicas and offer potential advantages of ambient processing of PEI aggregates, which would be of particular interest in view of applications such as bioactive component immobilization and surface patterning of silicate-based materials. It was found that the silica morphologies could be controlled accurately by simply adjusting the amount of methanol addition. Compared to the obvious nanofiber structure of silica (Figure 8A) formed in neat water, aqueous medium with $50 \mathrm{vol} \%$ methanol addition mediated the silica particles composed of beautiful unit ribbons (Figure 8B). The unit ribbons have a typical width of 1-2 micrometers and a length of more than 10 micrometers. Such simple methanol-mediated approach has been also extended to star PEI for achieving the new silica morphologies (Jin \& Yuan, 2006). For example, $0.5 \mathrm{wt} \%$ sPEI4-200 aggregates mediated the formation of very large and curved silica films composed of unit nanofibers (Figure 8C). In contrast, $50 \mathrm{vol} \%$ methanol addition in media for assembling sPEI4-200 aggregates led to the formation of well-defined fan-like silicas with very dense aggregation of unit fibers (Figure 8D). $0.3 \mathrm{wt} \%$ sPEI4-200 in a medium with $30 \mathrm{vol} \%$ methanol content directed fanlike silicas with relatively loose aggregation and flowerlike silicas with loose petals (Figure 8F). In contrast, only nanofiber- 
based silica films formed when using neat water as media (Figure 8E) under the same conditions. We also found that such morphological changes with methanol addition did not depend on the heating history of PEI aggregates formation, indicating that methanol-water media composition merely determined the PEI self-assembly. We propose that the addition of methanol in media could retard the nucleation of PEI crystalline, and thus the growth of crystallites was limited within relatively small domains. This slow and suppressed aggregation and/or crystallization process would be favorable to construct the ribbon-like or fan-like structure. This assumption was supported by our experimental observation. The aggregate formation in neat water media was observed to take several minutes when cooling the hot solutions of PEI5050 or sPEI4-200, whereas the complete aggregation in the methanol-modulation process usually needs several hours, especially for the systems with higher methanol contents.

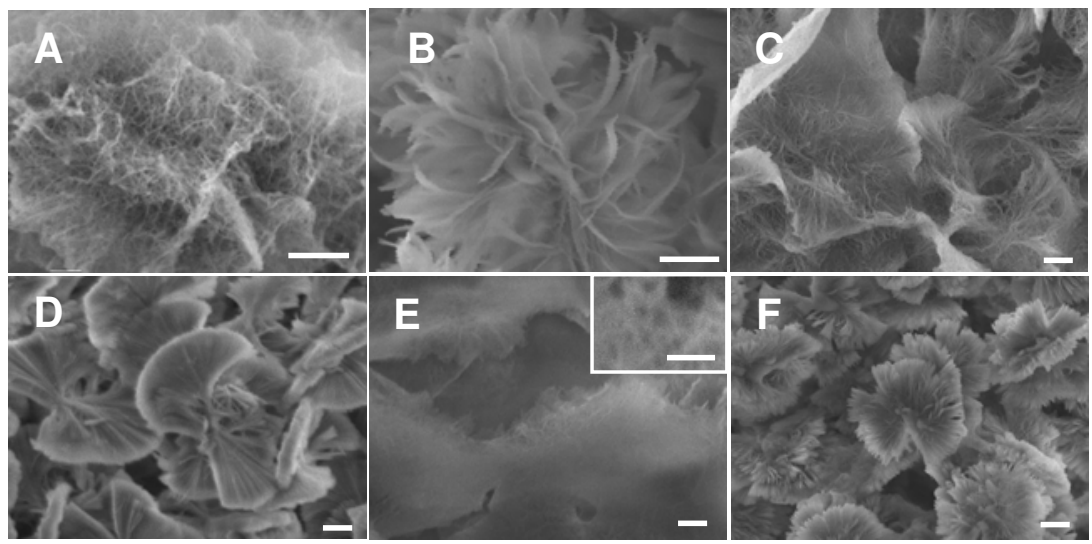

Fig. 8. Control of PEI@silica morphology by MeOH mediation. PEI@silicas were synthesized by using aggregates: (A) $1.0 \mathrm{wt} \%$ PEI5050 in water; (B) $1.0 \mathrm{wt} \% \mathbf{P 5 0 5 0}$ in a mixture of water$\mathrm{MeOH}$ ( $1 / 1$ in volume ratio); (C) $0.5 \mathrm{wt} \%$ sPEI4-200 in water; (D) $0.5 \mathrm{wt} \%$ sPEI4-200 in a mixture of water-MeOH (1/1 in volume ratio); (E) $0.3 \mathrm{wt} \%$ sPEI4-200 in water; (F) $0.3 \mathrm{wt} \%$ SPEI4-200 in a mixture of water-MeOH (30 vol\% $\mathrm{MeOH})$. The bars are $2 \mu \mathrm{m}$ for A-F and 500 $\mathrm{nm}$ for the inset of $\mathrm{E}$.

\subsubsection{Acid additives}

The ethyleneimine units of PEI could associate with acidic molecules by hydrogen bonding interaction to form complexes. Therefore, such complexation could also be used to control the PEI aggregation and subsequent direct silica morphologies (Jin \& Yuan, 2007a). We selected the acid molecules of $\mathrm{HCl}$, poly(ethylene glycol) bis(carboxymethyl) (BA) and tetra(p-sulfophenyl)porphyrin (TSPP) with functional protons 1, 2 and 4 in one molecule. Given that protonated segments of linear PEI are freely soluble in water, the partial protonation of linear PEI could allow the modification of crystalline aggregates of PEI, leading to the formation of new structure and morphology. The silicas formed without $\mathrm{HCl}$ addition showed silica network with dense nanofiber structure (Figure 9A). In contrast, silicification of $1 \mathrm{wt} \%$ PEI5050 aggregates prepared from $10^{-5} \mathrm{M} \mathrm{HCl}$ produced silicas composed of relatively looser network structure and unit nanofibers with increased diameter (Figure 9B). This could be attributed to the formation of PEI nanofibers with 
increased density or thickness of PEI amorphous shell due to the suitable protonation degree of PEI backbone by $\mathrm{HCl}$ addition. Further increase of the concentration of $\mathrm{HCl}$ was found to damage the nanofiber structure of silica. The silicas mediated by the aggregates prepared in $10^{-2} \mathrm{M} \mathrm{HCl}$ solution showed olive-like shape (Figure 9C). Many silica nanofibers of about $1 \mu \mathrm{m}$ length grew from the surface of the particles. Obviously, $\mathrm{HCl}$ addition in increased amount is capable of directing 3-demensional silica structures composed of silica nanofibers.
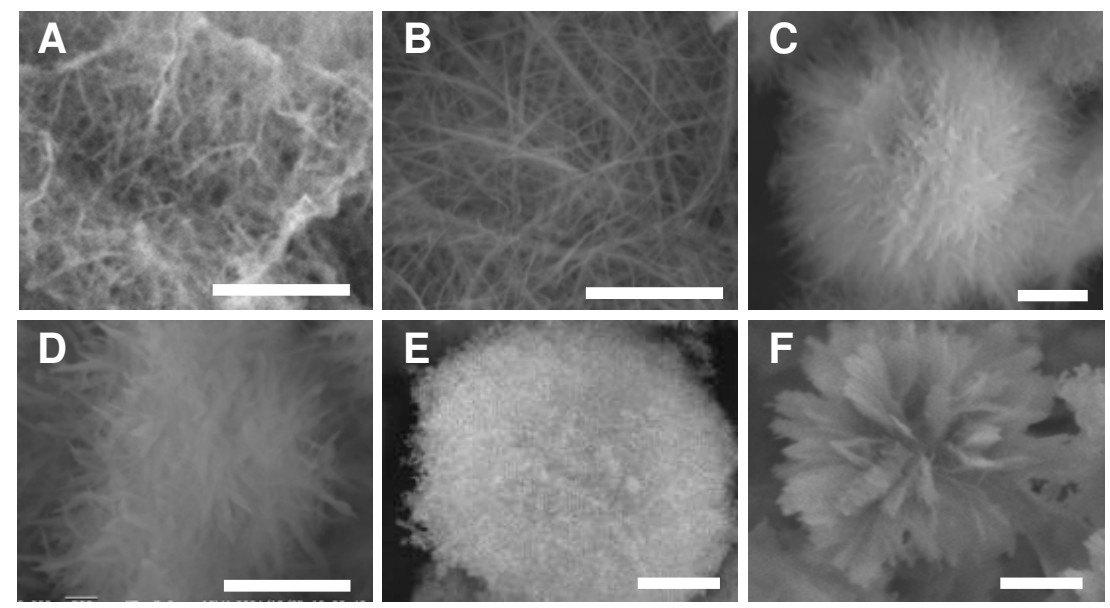

Fig. 9. Shaped PEI@silicas synthesized by templating PEI5050 aggregates without acid additive (A) and with the mediation of 10-5 $\mathrm{M} \mathrm{HCl}(\mathrm{B}), 10^{-2} \mathrm{M} \mathrm{HCl}(\mathrm{C}), 10^{-2} \mathrm{M} \mathrm{BA600}(\mathrm{D}), 0^{-2}$ M BA250 (E) and TSPP ([EI]/[TSPP]=1200/1, $30 \mathrm{vol} \% \mathrm{MeOH}$ addition) (F). The PEI5050 concentrations are 1.0 and $0.3 \mathrm{wt} \%$ for $(\mathrm{A}-\mathrm{E})$ and $(\mathrm{F})$, respectively. The bars are $2 \mu \mathrm{m}$ for each case.

Different to inorganic $\mathrm{HCl}$, addition of bifunctional organic acids, poly(ethylene glycol) bis(carboxymethyl) ethers with molecular weights of ca. 250 and 600 (denoted as BA250 and BA600) could adjust the properties and morphologies of the crystalline aggregates of linear PEI, by physical cross-linking via formation of hydrogen bonding. Upon silificifying the aggregates self-assembled from PEI by addition of 10-2 M BA600 (Figure 9D) and BA250 (Figure 9E), it was found that micro-scaled plate-like silica particles were formed. However, the nanostructures of particles showed the difference between BA600 and BA250 addition. The silica particles from BA250 addition appear much denser in comparison with the silicas mediated by BA600 association, and almost no fibrous structure could be observed from the silica particles obtained from BA250.

A four-armed star PEI with porphyrin core (p-sPEI4-240) can direct silica into a beautiful aster structure (Jin \& Yuan, 2005a), which is dramatically different to silica mediated from simple linear PEI. The specific aggregation of porphyrin residues was assumed to play the important role for affording the 3-D self-assembly of PEI crystalline unit. This assumption was exploited to design the silica morphology by incorporating TSPP (a porphyrin possessing four sulfonic groups) into linear PEI. By silicifying PEI505 aggregates formed in an aqueous system containing $30 \mathrm{vol} \%$ methanol, $0.3 \mathrm{wt} \%$ PEI505 and a trace of TSPP (in a molar ratio of EI/TSPP at 1200/1), the beautiful flower-like silica particles with micrometer 
size were achieved (Figure 9F). In the flower-like particles, many silica petals with the width of 500-1000 nm and the length of several micrometers grew from the center in a radiation way. Clearly, the participation of TSPP in the self-assembly of crystalline aggregates of PEI505 efficiently promoted the formation of 3-D silica structure (flower-like). This is consistent with the formation of 3-D aster silicas from p-sPEI4-240.

In addition to the impressive shape control, another important merit for TSPP mediation is that this process simultaneously produced the photo-functionalized hybrid silicas materials. The UV-vis spectrum of the stock solution of PEI and TSPP in methanol showed a typical spectroscopic line due to the molecular state of porphyrin. In contrast, the spectroscopic line of the trapped TSPP in the shaped silicas changed remarkably; the soret band became very broad with a red-shift from 418 to $423 \mathrm{~nm}$, and the Q-bands also shifted toward longer wavelengths, indicating that the porphyrin residues are in a stacking state in the shaped silica. For silicas mediated from TSPP addition, we suggested that two sets of interactions could be a cooperative trigger to induce subtle PEI self-assembly. One set is the association of TSPP with PEI by hydrogen bonding interaction, and the other set is the aggregation between prophyrin planes by $\pi-\pi$ stacking. These shaped silicas with PEI/TSPP are expected to be used in photonic, electronic and catalytic fields due to the porphyrin functions.

\subsubsection{Metal ions as additives}

Metal cations should be efficient candidates for regulating the nucleation and growth of LPEI crystals with defined morphologies, as PEI is a strong coordinator to form complexes (Zhu et al., 2007). The PEI aggregates with the mediation of metal ions were prepared by slowly cooling hot aqueous solutions of PEI containing three groups of metal cations with different valences (monovalent cations: $\mathrm{Li}^{+}, \mathrm{Na}^{+}, \mathrm{K}^{+}$; divalent cations: $\mathrm{Cu}^{2+}, \mathrm{Co}^{2+}, \mathrm{Zn}^{2+}, \mathrm{Mn}^{2+}$; trivalent cations: $\mathrm{Al}^{3+}, \mathrm{Eu}^{3+}, \mathrm{Fe}^{3+}, \mathrm{In}^{3+}$ ). The silicification was performed by mixing the aggregates with TMOS and methanol at room temperature for $40 \mathrm{~min}$. It was found that bulky, turbine-like and urchinlike silica, were produced by mediation of $\mathrm{Na}^{+}, \mathrm{Cu}^{2+}$ and $\mathrm{Al}^{3+}$ with the ratios of EI to metal ions of 20/1, respectively (Figure 10A, B and C). It seems that the $\mathrm{Na}^{+}$ion suppressed fiber formation completely. The cross-sectional transmission electron microscopy (TEM) image for $\mathrm{Cu}^{2+}$-mediated silica revealed that the unit blade of turbine-like is about $200 \mathrm{~nm}$ in width, and $20 \mathrm{~nm}$ in thickness. The urchin-like silicas from $\mathrm{Al}^{3+}$ addition showed a globular shape with numerous fine, needlelike fibers approximately $20 \mathrm{~nm}$ in width. Recently, detailed studies on the formation of 2-D turbine-like structures were performed by selecting $\mathrm{M}^{\mathrm{II}}\left(\mathrm{p}-\mathrm{TolSO}_{3}\right)_{2}$ as additives (Matsukizono et al., 2009). All silica structures from mediation of $\mathrm{Cu}^{\mathrm{II}}, \mathrm{Fe}^{\mathrm{II}}, \mathrm{Ni}{ }^{\mathrm{II}}, \mathrm{Co}^{\mathrm{II}}, \mathrm{Zn}{ }^{\mathrm{II}}, \mathrm{Mn}^{\mathrm{II}}$ are composed of leaf-like units of $200 \mathrm{~nm}$ width, which are bundled and grew in radial fashion to form 2-D turbine-like microstructures with a diameter of 5-6 $\mu \mathrm{m}$. In contrast, for non-coordinative ion, tetraethylammonium p-toluenesulfonate salts $\left(\mathrm{NEt}_{4}\left(\mathrm{p}-\mathrm{TolSO}_{3}\right)\right)$, only fibrous aggregates were observed. It is clear that these 2-D structures were induced by the coexisting metal salts with coordinative ability. The interactions between metal ions and amine groups seem to be the main factor for promoting 2-D shaped structures. Further studies indicated that the turbine structure could be controlled by changing the ratios of $[\mathrm{EI}] /\left[\mathrm{M}^{\mathrm{II}}\right]$ (Figure 10D, $\mathrm{E}$ and F) and self-assembly time of PEI-MII in water (Figure 10G, I and J). At 1000/70 of [EI]/ [NiII], 2-D turbine-like structures are obtained. These well-shaped structures became more swollen as $\mathrm{Ni}^{\mathrm{II}}$ ions decreased from 70 to $40 \mathrm{mM}$. Further decrease of $\mathrm{Ni}^{\mathrm{II}}$ concentration down to 20 $\mathrm{mM}$ leads to the formation of rougher aggregates of blade-like components in a more 
randomly bundled fashion, which is similar to those obtained from non-metal containing linear PEI aqueous solutions. In this system, growing times of PEI crystalline precipitates influenced the silica structures. For examples, the crystalline precipitates formed after 80 min lead to structured silica with two narrow fan-like edges. After that, new sheets were generated in both sides of each edge and these edges grew in a fan-like fashion with time. Finally, the fan closed to form turbine-like structures after $140 \mathrm{~min}$.
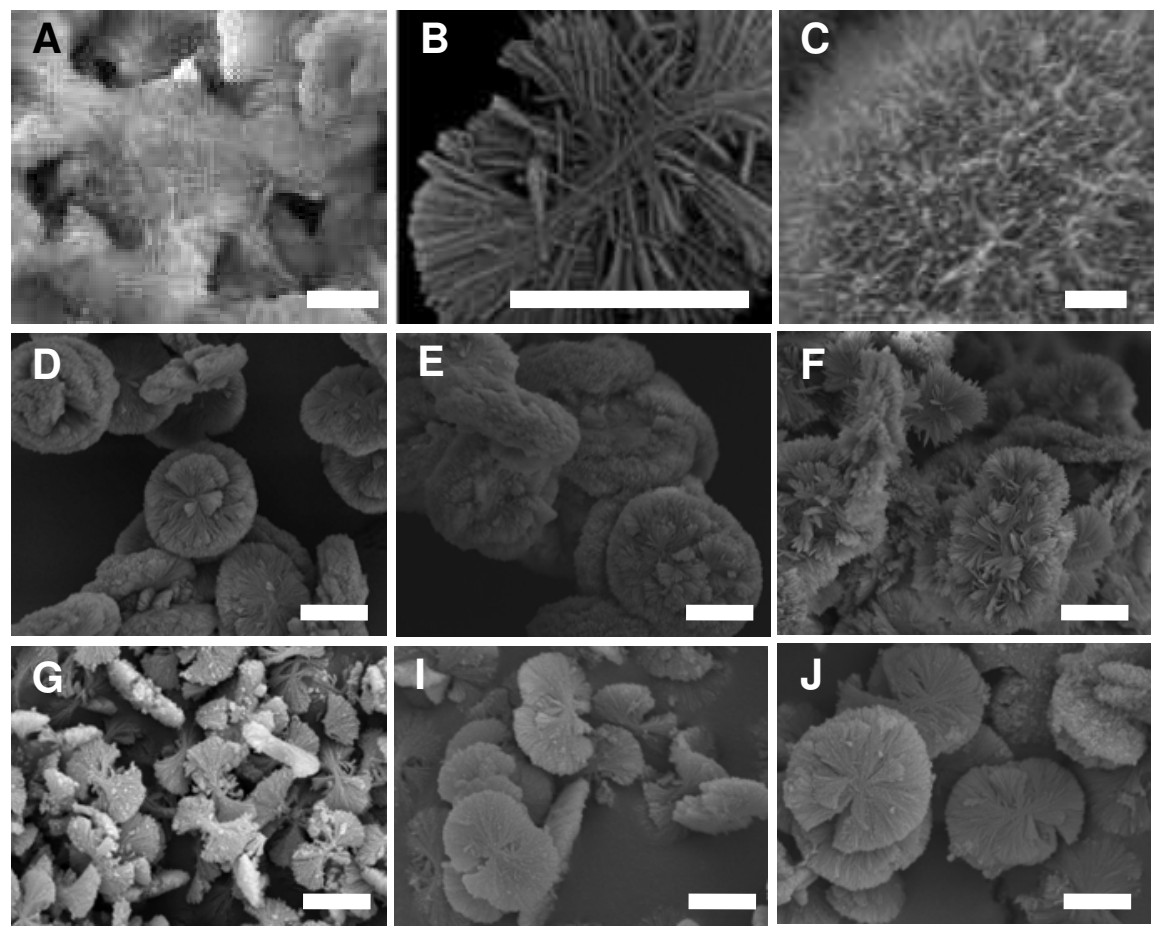

Fig. 10. SEM images of shaped silicas from self-assmebled PEI aggregates mediated from metal ions. (A), (B) and (C) are synthesized by the mediation of $\mathrm{Na}^{+}, \mathrm{Cu}^{2+}$ and $\mathrm{Al}^{3+}$, respectively, with the molar ratio of EI to metal ions of 20/1. (D), (E) and (F) are prepared by templating the aggregates from PEI5050 solution containing $\mathrm{Ni}^{\mathrm{II}}\left(\mathrm{p}-\mathrm{TolSO}^{3}\right)^{2}$ with the concentrations of 70, 40 and $20 \mathrm{mM}$ of $\mathrm{Ni}^{\mathrm{II}}$ ions ([EI] $\left.=1000 \mathrm{mM}\right)$, respectively. (G), (I) and (J) are morphological evolution of silica altered by pre-structured PEI5050 formed in Zn ${ }^{\mathrm{II}}(\mathrm{p}$ TolSO3) 2 aqueous solutions $([\mathrm{EI}]=1000 \mathrm{mM},[\mathrm{Zn}]=60 \mathrm{mM})$ at times of 80,110 and $140 \mathrm{~min}$, respectively. The bars are $2 \mu \mathrm{m}$ for each case.

\subsubsection{Physical field}

The programmed self-assembly of linear PEI could be also simply adjusted by changing the physical field for the formation of crystalline PEI (Yuan \& Jin, unpublished results). Using external physical field is of great interest due to that we don't need design and synthesize new polymer for shaping silica into complex morphologies and hierarchical nanostructure, which is relatively complex and time-consuming. Silica network composed of nanofibers of 
about $30 \mathrm{~nm}$ width was formed by silicifying the crystalline aggregates formed by naturally cooling the $1.0 \mathrm{wt} \%$ PEI5050 hot solution $\left(80^{\circ} \mathrm{C}\right)$ to room temperature (Figure 11A). In contrast, the width of fibrous silicas increased to about $500 \mathrm{~nm}-1 \mu \mathrm{m}$ when PEI aggregates were prepared by cooling the same hot solution with slow rate (Figure 11B). Obviously, the slowly cooling process enables the PEI molecules to have longer time to crystallize into objects with lager size. On the other hand, we also tried to freeze the molecular solution of PEI by immersing hot solution of PEI into mixture of ice-water and acetone-dry ice $\left(-70^{\circ} \mathrm{C}\right)$. After the temperature of frozen PEI solution was naturally back to room temperature, the PEI aggregation occurred. It is interesting that the sample from ice freeze showed the formation of silica plate (Figure 11C), and freeze from acetone-dry ice resulted in bulk-like silica composed of folded film (Figure 11D).

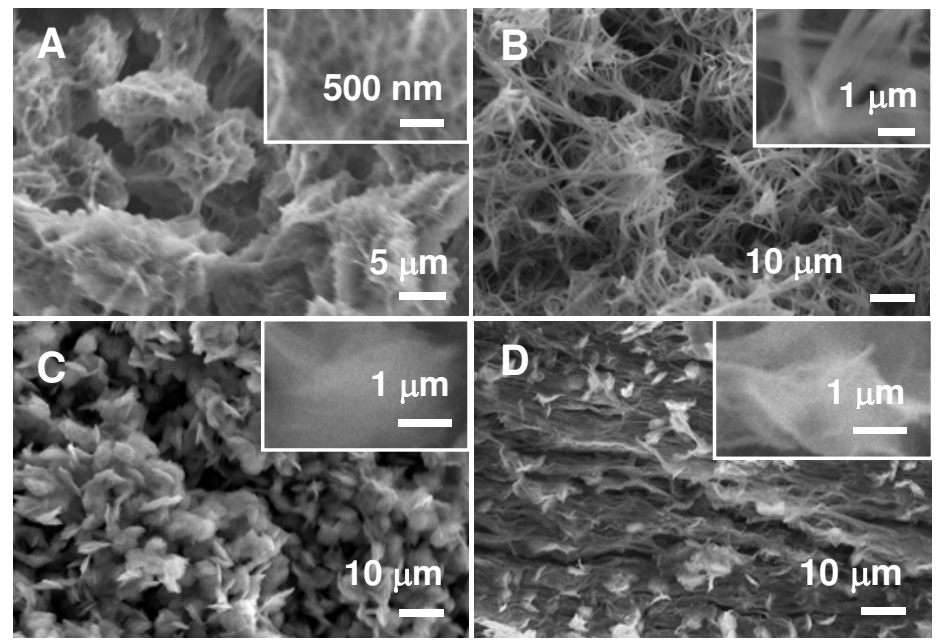

Fig. 11. Shaping silicas by physical field. (A) was prepared by using aggregates formed by naturally cooling $80^{\circ} \mathrm{C}$ aqueous solution of PEI5050 to room temperature; (B) was obtained by templating the aggregates formed by keeping $80^{\circ} \mathrm{C}$ aqueous solution of PEI5050 at $50^{\circ} \mathrm{C}$ for $1 \mathrm{~h}$ and then naturally down to room temperature; (C) and (D) were formed by using PEI aggregates prepared by immersing $80^{\circ} \mathrm{C}$ aqueous solution of PEI5050 into a bath of icewater and acetone/dry ice, respectively, and then allowing iced samples back to room temperature naturally. All samples have the same concentration of $1.0 \mathrm{wt} \%$ PEI5050.

\subsubsection{Fluorescent silica nanoparticles with controlled diameters}

Well-defined silica nanoparticles with controlled size and tunable functions are interesting especially for biomedical applications. Conventional Stöber method (Stöber et al. 1968) for the synthesis of silica nanoparticles requires harsh conditions and needs care for particle control. Recently, there have been some reports describing the biomimetic synthesis of silica spheres mediated by bio-polyamines or synthetic linear or dendrimer polyamines (Knecht \& Wright, 2004; Li et al., 2009), however, the precise particles size control and facile functionalization still is a challenge. By simply adjusting the media compositions for PEIs with linear backbone, we are able to generate the uniformed silica nanoparticles functionalized with acidic dyes by one-port manner (Jin \& Yuan, 2007b). By optimizing 

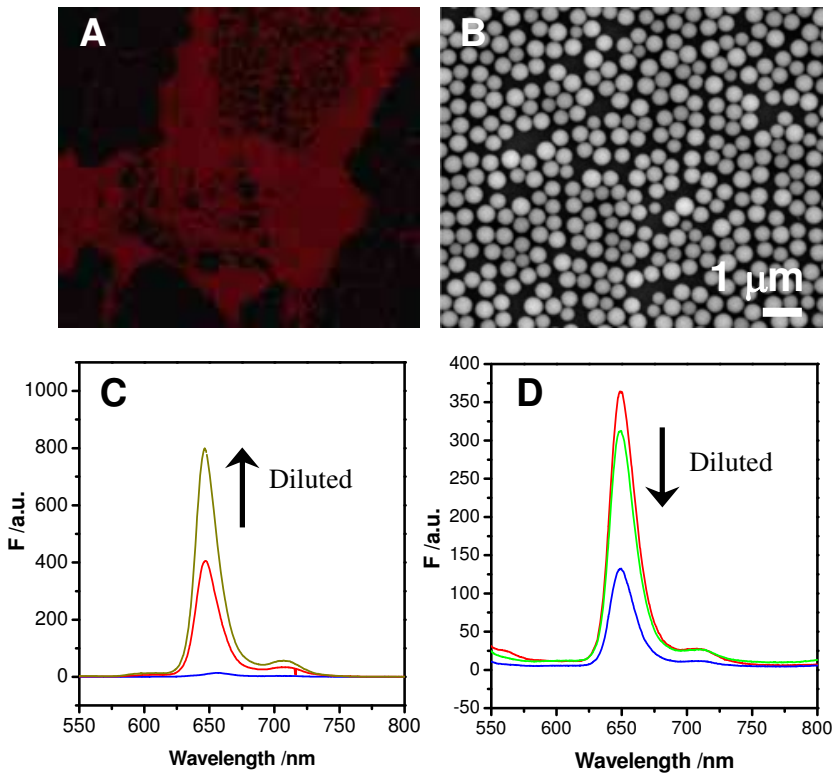

Fig. 12. Uniformed silica nanoparticles synthesized by the mediation of linear poly(ethyleneimine)s and dyes. (A) Fluorescent microscopic and (B) SEM images of silica nanoparticles prepared by using sPEI4-50/TSPP (1200/1 in molar ratio). (C) Fluorescence spectra of sPEI4-50/TSPP solution and (D) TSPP-entrapped silica spheres with diluting the concentrations.

medium composition of methanol/water to be $7 / 3$ in volume, the linear-backbone-based PEIs with different architectures and/or addition of TSPP directed the formation of monodisperse silica nanospheres with silicification reaction time of $1 \mathrm{~h}$ at room temperature (Figure 12A and B). The diameters of silica nanoparticles could be controlled from 50 to 700 $\mathrm{nm}$ by adjusting the polymer architectures, additives or solution conditions for silica mineralization. The attractive feature in our approach is that photofunctional dyes could be simultaneously and simply encapsulated into the resulting silica spheres. The precursor PEI/TSPP (1200/1) and silica nanoparticles by silicifying precursor PEI/TSPP showed the same peak position of absorption spectra, indicating that the porphyrin residues entrapped in the silica spheres exist as molecularly distributed state (i.e., isolated without stacking). This is very different to that of aster- and flower-like silicas prepared from p-sPEI-240 and PEI505/TSPP (1200/1 in molar ratio), respectively. Fiber-based 3-D silicas were synthesized by templating the crystalline PEI aggregates formed in pure water (p-sPEI-240) or in methanol/water (5/5 in vol., PEI505/TSPP). In contrast, the silica nanoparticles were formed by using a medium of methanol/water (7/3 in vol.), in which PEI do not crystallize due to the excess presence of methanol. To further understand the spectroscopic properties of these silica nanoparticles, the dependence of intensities of absorption and emission on the concentrations was examined. We found that absorption intensities of both PEI/TSPP precursor and PEI/TSPP/silica nanoparticles increased with increasing concentrations (Jin \& Yuan, 2007b). However, the emissions of PEI/TSPP precursor and PEI/TSPP/silica nanoparticles in methanol showed different behavior upon concentration change. The 
emission intensity (at $650 \mathrm{~nm}$ ) of the original methanol solution of PEI/TSPP precursor is very weak, compared to those from diluted solutions (Figure 12C). This is due to the dynamic-induced self-quenching of TSPP at higher concentration, suggesting that porphyrin residues are not tethered to the star polymer and thus are in movement with collision. However, the emission intensity of the PEI/TSPP/silica nanoparticles in methanol increased upon increasing concentrations (Figure 12D), indicating that TSPP residues with PEI were almost completely encapsulated in the silica nanospheres and existed as isolated state. The dye entrapped into silica nanospheres did not show bleach even dispersed in methanol for over one year. Thus these novel TSPP-functionalized silica nanoparticles would be superior to some of conventional dye-encapsulated silica nanoparticles based on Stöber routes by either using silica source with chemically-bonded-dyes or physically doping dyes into silica network, in which dye incorporation is not easily controllable (Chan et al., 2004).

\subsection{Linear PEI for mineralization of other oxides, metals and salts}

Titanium oxides, as one of the most useful semiconductors, have been applied in a wide area due to their many promising properties. Conventional process has made progress on tailoring $\mathrm{TiO}_{2}$ into precisely controlled nanostructure, however titania deposition normally occurred under harsh conditions. Inspired by biosilica formation, biomimetic synthesis of titania materials have been attempted by using various biologically-derived molecules or synthetic polyamines (Brutchey \& Morse, 2008). However, it remains difficult to construct $\mathrm{TiO}_{2}$ materials with definite morphologies (i.e. fiber-like) and characteristic function by this process. Our recent work demonstrated that well-shaped fibrous networks of PEI@TiO hybrids (Figure 13) could be controllably prepared in an aqueous solution at room temperature by using crystalline PEI aggregates as a regulator and water-soluble titanium bislactate as source (Zhu \& Jin, 2010). Fibrous hybrids were found to be composed of anatase nano crystallites (Figure 13B and C) and linear PEI with a regularly-layered structure. The morphologies and structures of $\mathrm{TiO}_{2}-\mathrm{PEI}$ hybrids depended on $\mathrm{pH}$ of reaction systems and concentrations of PEI and titania source. Recently, Zhao and co-workers also described using fibrous PEI aggregates as template to direct the low-temperature formation of nano-branched aluminum-magnesium hydroxide (Xiang et al., 2008).
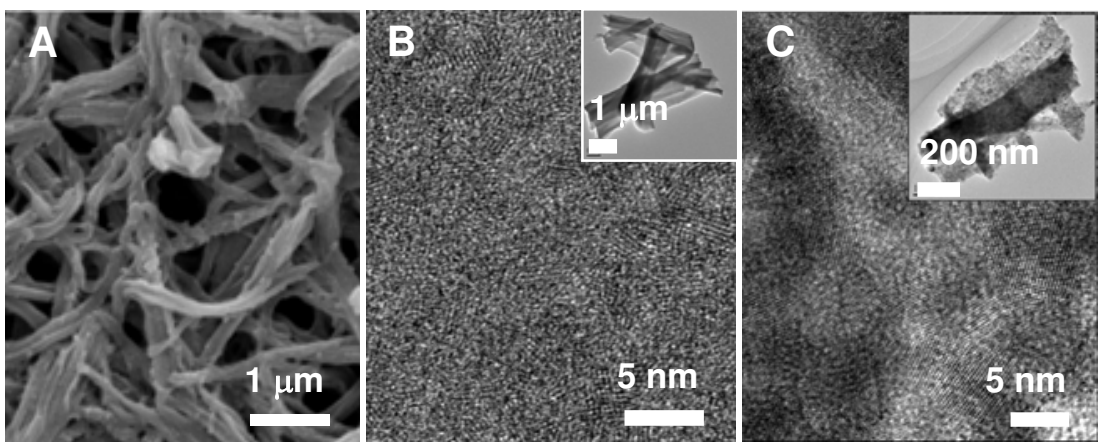

Fig. 13. (A) SEM image of fibrous PEI@titania hybrids synthesized by simple and efficient aqueous process regulated by linear polyethyleneimine aggregates, (B) TEM (inset) and HRTEM image of synthesized PEI@titania, indicating the formation of very tiny crystalline domains and (C) TEM (inset) and HRTEM images of fibrous titania formed by calcining PEI@titania at $500{ }^{\circ} \mathrm{C}$. 
On the other hand, polymers with linear PEI backbone have been also examined to mineralize metals into various structure and morphologies. For example, with the use of low-molecular-weight linear PEI or alkylated PEI (with repeated units of EI of around 8) to serve as a reducing agent and a protective agent, $\mathrm{HAuCl}_{4}$ was reported to be induced to form gold nanoparticles and nanoplates through either a thermal process or room temperature (Chen et al., 2007). We are interested in using high-molecular-weight linear PEI with self-assembled crystalline property for reduction and stabilization of metal ion. By simply mixing the aqueous dispersion of crystalline PEI aggregates with $\mathrm{AgNO}_{3}$ aqueous solution at room temperature, an Ag nanoparticles-PEI paste could be obtained. The macroporous silver frameworks have been achieved by calcining the Ag nanoparticles-PEI pastes (Jin \& Yuan, 2005c). We found that the porous silver frameworks could be tunable into dome-like shapes with the inner chambers or monoliths with shape-preservation by simply adjusting some synthesis parameters.

Recently, Taubert and co-workers (Shkilnyy et al., 2008) reported that PEI could be an efficient template for the controlled mineralization of calcium phosphate. It was found that spherical calcium phosphate/polymer hybrid particles were formed at $\mathrm{pH}$ values above 8 through a mineralization-trapping pathway, where small calcium phosphate particles formed at the initial step were stabilized by protonated PEI. Comparative studies revealed that branched and linear PEIs did not show significant difference for calcium phosphate mineralization, since PEIs were only used as $\mathrm{pH}$-responsive cationic polymer for modifying crystal growth of calcium phosphate. Self-assembling property of linear PEI due to aqueous crystallization was not involved in the morphological creation of calcium phosphate, as seen in the mineralization of silica, titania or metals.

\subsection{PEI@oxides as nanoreactors for generating metal nanoparticles}

One of important characters of our PEI@oxides materials are that the PEI occluded in hybrids is still available for subsequent chemical reactions, leading to the facile synthesis of novel composite materials. The central PEI entrapped in the silica fiber could be used as a nanoreactor to synthesize metallic nanostructures (Yuan et al. 2006). The reduction of $\mathrm{Na}_{2} \mathrm{PtCl}_{4}$ was simply performed by keeping an aqueous mixture of PEI@silica nanofiber and $\mathrm{Na}_{2} \mathrm{PtCl}_{4}$ for $30 \mathrm{~min}$ at room temperature and then aged at $80^{\circ} \mathrm{C}$ for another $30 \mathrm{~min}$, without any additive reducing agents. XRD measurement indicated the formation of a face-centered cubic (fcc) lattice of the platinum crystal structure. HRTEM studies demonstrated the formation of Pt@silica nanocables with the Pt central nanowires of about $3 \mathrm{~nm}$ in width (Figure 14A). Surprisingly, when irradiated with a strong electron beam, the Pt nanowire in the silica nanotube broken into individual nanoparticles (Figure 14B). The in situ formation of Pt and Au nanoparticles in PEI@silica prepared using water glass as silica source has also been successfully achieved (Zhu \& Jin, 2008). These metal nanoparticles functionalized silica materials were expected to have potentials for catalysis or optic application. Furthermore, PEI residues in the $\mathrm{PEI} @ \mathrm{TiO}_{2}$ hybrids have been also exploited to reduce $\mathrm{Na}_{2} \mathrm{PtCl}_{4}$ into $\mathrm{Pt}$ nanoparticles by simply mixing $\mathrm{PEI} @ \mathrm{TiO}_{2}$ with the reactants at room-temperature (Zhu \& Jin, 2010). TEM studies indicated that the fibrous morphologies remained undestroyed after the formation of metallic nanoparticles (Figure 14E). The further HRTEM images showed that the $\mathrm{Pt}$ nanoparticles in situ formed have a typical diameter of about $3 \mathrm{~nm}$, are homogeneously distributed in the hybrid fibers (Figure 14F). These nanostructured $\mathrm{TiO}_{2}$ doped with $\mathrm{Pt}$ nanoparticles revealed visible light responsible photocatalytic power in decolorization of dyes. 


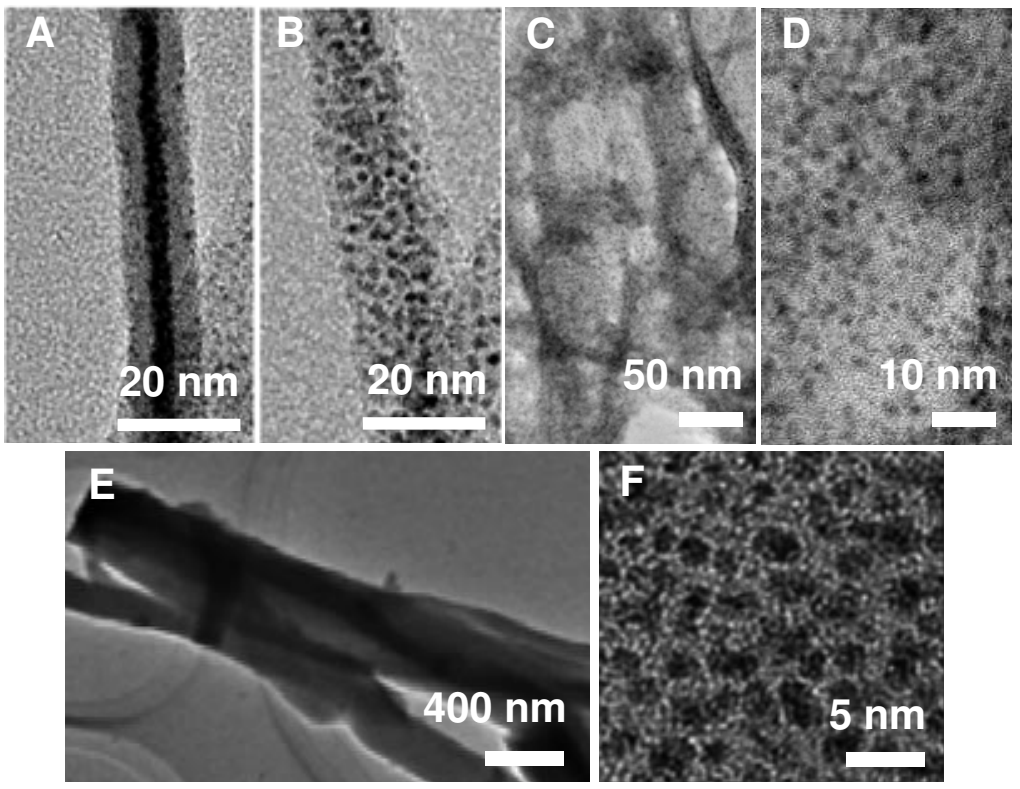

Fig. 14. PEI@silica or PEI@titania hybrids as microreactors for in situ formation of Pt nanoparticles. (A and B) PEI@silica hybrid from TMOS source; (C and D) PEI@silica hybrids from water glass as source; (E and F) PEI@titania hybrids.

\section{Concluding remarks and future outlook}

It is important for device and sensor application to biomimetically construct nanostructured ceramic surface on substrates. It has been a number of reports describing the biomimetic formation of silica (Yang et al., 2009; Rai \& Perry, 2009) and titania (Kharlampieva et al., 2008) film on the solid substrates. Although some reports have been successful to control film thickness, particles packing, or patterns, constructing the silica film with high-degree controllable nanostructure on the arbitrary substrates is still a challenge. Very recently, we have successfully constructed the silica nanograss on the arbitrary substrates with any shapes by extending the programmed self-assembly of linear PEI from solution (silica powder) to interface (silica nanograss) (Figure 15) (Jin \& Yuan, 2009). Such a process has been expanded for the formation of nanofiber-based titania surface, which demonstrated the photoresponsive surface wettability (Yuan \& Jin, 2010a). These novel interface materials with controlled nanostructure and surface morphology are expected to have potential applications as microreactors, sensors, microfluidic devices, surface with designer wettability (Yuan \& Jin, 2010a; 2010b) and so on. Moreover, the further functionalization of such silica nanograss is possible by exploiting the chemistry of PEI and conventional silica, allowing our interface materials to be applicable in a wide variety of emerging nanotechnology. On the other hand, although the biomimetic silicas have many amazing features including ambient-conditions synthesis, potentially precise control over nanostructure and good biocompatibility, the commercial application still remains a big challenge. One of major reason is that most of currently-developed systems for biomimetic 
silica formation are not easy to scale up, and suffer from high cost, low reproducibility and relatively poor morphogenesis. Recently, we have optimized the conditions to achieve a low-cost and reproducible synthesis of several hundred gram scale of silica nano ribbons. Silicification was performed in neat water under room temperature by using a cheap, commercially-available silica source. This achievement on biomimetic silica synthesis would make it possible to develop the related technological applications in a wide range of fields.
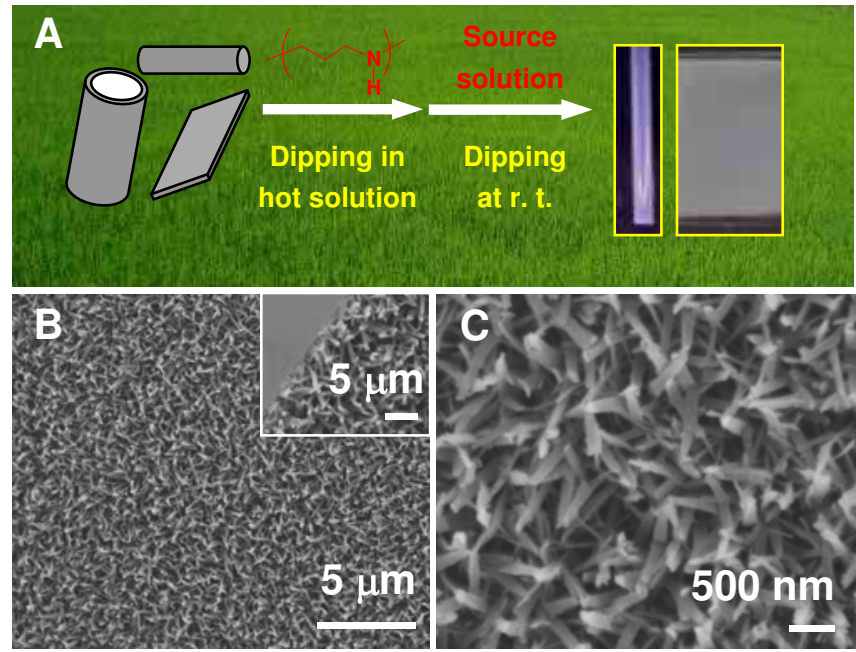

Fig. 15. PEI@silica nanograss on arbitrary substrates with. (A) two-step processing for growing the PEI@silica nanoribbons on substrates; (B) a representative SEM image of PEI@silica nanograss, the inset is a cross-section image of nanograss; (C) high-magnification SEM image of PEI@silica nanograss, indicating the blade-like morphology

\section{References}

Akiyama, Y.; Harada, A.; Nagasaki, Y. \& Kataoka, K. (2000). Synthesis of poly(ethylene glycol)-block-poly(ethylenimine) possessing an acetal group at the PEG end, Macromolecules, 33, 5841-5845.

Brunner, E.; Lutz, K. \& Sumper, M. (2004). Biomimetic synthesis of silica nanospheres depends on the aggregation and phase separation of polyamines in aqueous solution, Phys. Chem. Chem. Phys., 6, 854-857.

Brutchey, R.L. \& Morse, D.E. (2008). Silicattein and the translation of its molecular mechanism of biosilicification into low temperature nanomaterial synthesis, Chem. Rev., 108, 4915-4934.

Cha, J.N.; Shimizu, K.; Zhou, Y.; Christiansen, S.C.; Chmelka, B.F.; Stucky, G.D. \& Morse, D.E. (1999). Silicatein filaments and subunits from a marine sponge direct the polymerization of silica and silicones in vitro, Proc. Nat. Acad. Sci. USA, 96, 361-365.

Cha, J.N.; Stucky, G.D.; Morse, D.E. \& Deming, T.J. (2000). Biomimetic synthesis of ordered silica structures mediated by block copolypeptides, Nature, 403, 289-292. 
Chan, Y.; Zimmer, J.P.; Stroh, M.; Steckel, J.S.; Jain, R.K. \& Bawendi, M.G. (2004). Incorporation of luminescent nanocrystals into monodisperse core-shell silica microspheres, Adv. Mater., 16, 2092-2097.

Chatani, Y.; Tadokoro, H.; Saegusa, T. \& Ikeda, H. (1981). Structural studies of poly(ethylenimine). 1. Structures of two hydrates of poly(ethylenimine): sesquihydrate and dehydrate, Macromolecules, 14, 315-321.

Chatani, Y.; Kobatake, T.; Tadokoro, H. \& Tanaka, R. (1982). Structural studies of poly(ethylenimine). 2. Double-stranded helical chains in the anhydrate, Macromolecules, 15, 170-176.

Chatani, Y.; Kobatake, T. \& Tadokoro, H. (1983). Structural studies of poly(ethylenimine). 3. Structural characterization of anhydrous and hydrous states and crystal structure of the hemihydrate, Macromolecules, 16, 199-204.

Chen, C.C.; Hsu, C.H. \& Kuo, P.L. (2007). Effects of alkylated polyethylenimines on the formation of gold nanoplates, Langmuir, 23, 6801-6806.

Croce, G.; Frache, A.; Milanesio, M.; Marchese, L.; Causà, M.; Viterbo, D.; Barbaglia, A.; Bolis, V.; Bavestrello, G.; Cerrano, C.; Benatti, U.; Pozzolini, M.; Giovine, M. \& Amenitsch, H. (2004). Structural characterization of siliceous spicules from marine sponges, Biophys. el, 86, 526-534.

Croce, G.; Viterbo, D.; Milanesio, M. \& Amenitsch, H. (2007). A mesoporous pattern created by nature in spicules from Thetya aurantium sponge, Biophys. $L$, 92, 288-292.

Davis, M.E. (2002). Ordered porous materials for emerging applications, Nature, 417, 813821.

Field, C.B.; Behrenfeld, M.J.; Randerson, J.T. \& Falkowski, P. (1998). Primary production of the biosphere: integrating terrestrial and oceanic components, Science, 281, 237-240.

Fuhrmann, T.; Landwehr, S.; El Rharbi-Kucki, M. \& Sumper, M. (2004). Diatoms as living photonic crystals, Appl. Phys. B, 78, 257-6028.

Hashida, T.; Tashiro, K.; Aoshima, S. \& Inaki, Y. (2002). Structural investigation on waterinduced phase transitions of poly(ethylene imine). 1. Time-resolved infrared spectral measurements in the hydration process, Macromolecules, 35, 4330- 4336.

Hildebrand, M. (2008). Diatoms, Biomineralization processes, and genomics, Chem. Rev., 108, 4855-4874.

Hsiue, G.H.; Chiang, H.Z.; Wang, C.H. \& Juang, T.M. (2006). Nonviral gene carriers based on diblock copolymers of poly(2-ethyl-2oxazoline) and linear polyethyleneimine, Bioconj. Chem., 17, 781-786.

Ji, Q.; Iwaura, R.; Kogiso, M.; Jung, J.H.; Yoshida, K. \& Shimizu, T. (2004). Direct sol-gel replication without catalyst in an aqueous gel system: from a lipid nanotube with a single bilayer wall to a uniform silica hollow cylinder with an ultrathin wall, Chem. Mater., 16, 250-254.

Jin, R.H. \& Motoyoshi, K. (1999). Porphyrin-centered water-soluble star-shaped polymers: poly(N-acetylethylenimine) and poly(ethylenimine) arms, $d$ Porphyrins Phthalocyanines, 3, 60-64.

Jin, R.H. (2002a). Controlled location of porphyrin in aqueous micelles self-assembled from porphyrin centered amphiphilic star poly(oxazolines), Adv. Mater., 14, 889-892.

Jin, R.H. (2002b). Silica-polyoxazoline hybrid with nanosized hollow enclosing porphyrin in hybrid walls, Chem. Commun., 198-199. 
Jin, R.H. (2003a). Self-assembly of porphyrin-centered amphiphilic star block copolymer into polymeric vesicular aggregates, Macromol. Chem. Phys., 204, 403-409.

Jin, R.H. (2003b). Colloidal crystalline polymer generated in situ from growing star poly(oxazolines), el Mater. Chem., 13, 672-675.

Jin, R.H. (2003c). Functional polymeric micelles formed from a novel cationic star block copolymer, ChemPhysChem, 4, 1118-1121.

Jin, R.H. (2004). Water soluble star block poly(oxazoline) with porphyrin label: a unique emulsion and its shape direction, I Mater. Chem., 14, 320-327.

Jin, R.H. \& Yuan, J.J. (2005a). Synthesis of poly(ethyleneimine)s-silica hybrid particles with complex shapes and hierarchical structures, Chem. Commun., 1399- 1401.

Jin, R.H. \& Yuan, J.J. (2005b). Simple synthesis of hierarchically structured silicas by poly(ethyleneimine) aggregates pre-organized by media modulation, Macromol. Chem. Phys., 206, 2160-2170.

Jin, R.H. \& Yuan, J.J. (2005c). Fabrication of silver porous frameworks using poly(ethyleneimine) hydrogel as a soft sacrificial template, cl Mater. Chem., 15, 45134517.

Jin, R.H. \& Yuan, J.J. (2006). Shaped silicas transcribed from aggregates of four-armed star polyethyleneimine with a benzene core, Chem. Mater., 18, 3390-3396.

Jin, R.H. \& Yuan, J.J. (2007a). Hierarchically structured silica from mediation of linear poly(ethyleneimine) incorporated with acidic/basic additives, Polym. el, 39, 464-470.

Jin, R.H. \& Yuan, J.J. (2007b) One-pot and rapid synthesis of uniformed silica spheres via mediation of linear poly(ethyleneimine)s and dyes, Polym. cl, 39, 822- 827.

Jin, R.H., \& Yuan, J.J. (2009) Biomimetically controlled formation of nanotextured silica/titania films on arbitrary substrates and their tunable surface function, $A d v$. Mater., 21, 3750-3753.

Johnson, J.R.; Spikowski, J. \& Schiraldi, D.A. (2009). Mineralization of clay/polymer aerogels: a bioinspired approach to composite reinforcement, ACS Appl. Mater. Interfaces, 1, 1305-1309.

Kakuda, H.; Okada, T. \& Hasegawa, T. (2009). Temperature-induced molecular structural changes of linear polyethylene imine in water studied by mid-infrared and nearinfrared spectroscopies, el Phys. Chem. B, 113, 13910-13916.

Kharlampieva, E.; Tsukruk, T.; Slocik, J.M.; Ko, H.; Poulsen, N.; Naik, R.R.; Kröger, N. \& Tsukruk, V.V. (2008). Bioenabled surface-mediated growth of titania nanoparticles, Adv. Mater., 20, 3274-3279.

Knecht, M.R. \& Wright, D.W. (2004). Dendrimer-mediated formation of multicomponent nanospheres, Chem. Mater., 16, 4890-4895,

Krasko, A.; Lorenz, B.; Batel, R.; Schröder, H.C.; Müller, I.M. \& Müller, W.E.G. (2000). Expression of silicatein and collagen genes in the marine sponge Suberites domuncula is controlled by silicate and myotrophin, Eur. I Biochem., 267, 48784887, 4855-4874.

Kresge, C.T.; Leonowicz, M.E.; Roth, W.J.; Vartuli, J.C. \& Beck, J.S. (1992). Ordered mesoporous molecular sieves synthesized by a liquid-crystal template mechanism, Nature, 359, 710-712.

Kröger, N.; Bergsdorf, C. \& Sumper, M. (1994). A new calcium-binding glycoprotein family constitutes a major diatom cell wall component, EMBO cI, 13, 4676- 4683. 
Kröger, N.; Bergsdorf, C. \& Sumper, M. (1996). Frustulins: domain conservation in a protein family associated with diatom cell walls, Eur. el Biochem., 239, 259-284.

Kröger, N.; Lehmann, G.; Rachel, R. \& Sumper, M. (1997). Characterization of a 200-kDa diatom protein that is specifically associated with a silica-based substructure of the cell wall, Eur. el Biochem., 250, 99-105.

Kröger, N.; Deutzmann, R. \& Sumper, M. (1999). Polycationic peptides from diatom biosilica that direct silica nanosphere formation, Science, 286, 1129-1132.

Kröger, N. \& Wetherbee, R. (2000a). Pleuralins are involved in theca differentiation in the diatom Cylindrotheca fusiformis, Protist, 151, 263-273.

Kröger, N.; Deutzmann, R.; Bergsdorf, C. \& Sumper, M. (2000b). Species-specific polyamines from diatoms control silica morphology, Proc. Natl. Acad. Sci. U.S.A., 97, 1413314138.

Kröger, N.; Deutzmann, R. \& Sumper, M. (2001). Silica-precipitating peptides from diatoms: The chemical structure of silaffin-1A from Cylindrotheca fusiformis, I Bio. Chem., 276, 26066-27070.

Kröger, N.; Lorenz, S.; Brunner, E. \& Sumper, M. (2002). Self-assembly of highly phosphorylated silaffins and their function in biosilica morphogenesis, Science, 298, 584-586.

Kröger, N. \& Poulsen, N. (2008). Diatoms-from cell wall biogenesis to nanotechnology, Ann. Rev. Gene., 42, 83-107.

Li, X.; Yang, T.; Gao, Q.; Yuan, J. \& Cheng, S. (2009). Biomimetic synthesis of copolymersilica nanoparticles with tunable compositions and surface property, cl Colloid Interface Sci., 338, 99-104.

Matsukizono, H.; Zhu, P.X.; Fukazawa, N. \& Jin, R.H. (2009). Turbine-like structured silica transcribed simply by pre-structured crystallites of linear poly(ethyleneimine) bounded with metal ions, CrystEngComm, 11, 2695-2700.

Menzel, H.; Horstmann, S.; Behrens, P.; Bärnreuther, P.; Krueger, I. \& Jahns, M. (2003). Chemical properties of polyamines with relevance to the biomineralization of silica, Chem. Commun., 2994-2995.

Merchant, S.A.; Tran, T.O.; Meredith, M.T.; Cline, T.C.; Glatzhofer, D.T. \& Schmidtke, D.W. (2009). High-sensitivity smperometric biosensors based on ferrocene-modified linear poly(ethylenimine), Langmuir, 25, 7736-7742.

Milligan, A.J. \& Morel, F.M.M. (2002). A proton buffering role for silica in diatoms. Science, 297, 1848-1850.

Müller, W.E.G.; Rothenberger, M.; Boreiko, A.; Tremel, W.; Reiber, A. \& Schröder, H.C. (2005). Formation of siliceous spicules in the marine demosponge Suberites domuncula, Cell and Tissue Res., 321, 285-297.

Müller, W.E.G.; Belikov, S.I.; Tremel, W.; Perry, C.C.; Gieskes, W.W.C.; Boreiko, A. \& Schröder, H.C. (2006). Siliceous spicules in marine demosponges (example Suberites domuncula), Micron, 37,107-120.

Murr, M.M. \& Morse, D.E. (2005). Fractal intermediates in the self-assembly of silicatein filaments, Proc. Nat. Acad. Sci. USA, 102, 11657-11662.

Navarro, S.; Shkilnyy, A.; Tiersch, B.; Taubert, A. \& Menzel, H. (2009). Preparation, characterization, and thermal gelation of amphiphilic alkyl-poly(ethyleneimine), Langmuir, 25, 10558-10566. 
Patel, P.A.; Eckart, J.; Advincula, M.C.; Goldberg, A.J. \& Mather, P.T. (2009). Rapid synthesis of polymer-silica hybrid nanofibers by biomimetic mineralization, Polymer, 50, 1214-1222.

Patwardhan, S.V.; Clarson, S.J. \& Perry, C.C. (2005). On the role(s) of additives in bioinspired silicification, Chem. Commun., 1113-1121.

Perry, C.C. \& Keeling-Tucker, T. (2000). Biosilicification: The role of the organic matrix in structure control, el Bio. Inorg. Chem., 5, 537-550.

Pohnert, G. (2002). Biomineralization in diatoms mediated through peptide- and polyamineassisted condensation of silica, Angew Chem. Int. Ed., 41, 3167- 3169.

Pouget, E.; Dujardin, E.; Cavalier, A.; Moreac, A.; Valery, C.; Marchi-Artzner, V.; Weiss, T.; Renault, A.; Paternostre, M. \& Artzner, F. (2007). Hierarchical architectures by synergy between dynamical template self-assembly and biomineralization, Nat. Mater., 6, 434-439.

Poulsen, N.; Sumper, M. \& Kröger, N. (2003). Biosilica formation in diatoms: Characterization of native silaffin-2 and its role in silica morphogenesis, Proc. Natl. Acad. Sci. U.S.A., 100, 12075-12080.

Rai, A. \& Perry, C.C. (2009). Fabrication of tuneable thickness silica films on solid surfaces using amines and proteins, Silicon, 1, 91-101.

Saegusa, T.; Kobayashi,S. \& Yamada, A. (1975). Graft copolymerization of 2-methyl-2oxazoline onto chloromethylated polystyrene and hydrolysis of graft copolymer to a chelating resin of poly(styrene-g-ethylenimine), Macromolecules, 8, 390- 396.

Schmidt, D.J.; Cebeci, F.C.; Kalcioglu, Z.I.; Wyman, S.G.; Ortiz, C.; Vliet, K.J.V. \& Hammond, P.T. (2009). Electrochemically controlled swelling and mechanical properties of a polymer nanocomposite, ACS Nano, 3, 2207-2216.

Schröder, H.C.; Boreiko, A.; Korzhev, M.; Tahir, M.N.; Tremel, W.; Eckert, C.; Ushijima, H.; Müller, I.M. \& Müller, W.E.G. (2006). Co-expression and functional interaction of silicatein with galectin: Matrix-guided formation of siliceous spicules in the marine demosponge Suberites domuncula, el Bio. Chem., 281, 12001- 12009.

Schröder, H.C.; Wang, X.; Tremel, W.; Ushijima, H. \& Müller, W.E.G. (2008). Biofabrication of biosilica-glass by living organisms, Nat. Prod. Rep., 25, 455-474.

Shimizu, K.; Cha, J.; Stucky, G.D. \& Morse, D.E. (1998). Silicatein a: Cathepsin L-like protein in sponge biosilica, Proc. Nat. Acad. Sci. USA, 95, 6234-6238.

Shkilnyy, A.; Friedrich, A.; Tiersch, B.; Schone, S.; Fechner, M.; Koetz, J.; Schlapfer, C.-W. \& Taubert, A. (2008). Poly(ethylene imine)-controlled calcium phosphate mineralization, Langmuir, 24, 2102-2109.

Sumper, M. (2002). A phase separation model for the nanopatterning of diatom biosilica, Science, 295, 2430-2433.

Sumper, M. \& Kröger, N. (2004a). Silica formation in diatoms: The function of long-chain polyamines and silaffins, el Mater. Chem., 14, 2059-2065.

Sumper, M. (2004b). Biomimetic patterning of silica by long-chain polyamines, Angew Chem. Int. Ed, 43, 2251-2254.

Sumper, M. \& Lehmann, G. (2006). Silica pattern formation in diatoms: Species-specific polyamine biosynthesis, ChemBioChem, 7, 1419-1427.

Smetacek, V. (1999). Diatoms and the ocean carbon cycle, Protist, 150, 25-32.

Stöber, W.; Fink, A. \& Bohn, E. (1968). Controlled growth of monodisperse silica spheres in the micron size range, el Colloid Interface Sci., 26, 62-69. 
Tréguer, P.; Nelson, D.M.; van Bennekom, A.J.; DeMaster, D.J.; Leynaert, A. \& Quéguiner, B. (1995).The silica balance in the world ocean: a re-estimate, Science, 268, 375-379.

van Bommel, K.J.C. \& Shinkai, S. (2002). Silica transcription in the absence of a solution catalyst: the surface mechanism, Langmuir, 18, 4544-4548.

van Bommel, K.J.C.; Friggeri, A. \& Shinkai, S. (2003). Organic templates for the generation of inorganic materials, Angew Chem. Int. Ed, 42, 980-999.

van de Poll, W.H.; Vrieling, E.G. \& Gieskes, W.W.C. (1999). Location and expression of frustulins in the pennate diatoms Cylindrotheca fusiformis, Navicula pelliculosa, and Navicula salinarum (Bacillariophyceae), el Phycol., 35, 1044-1053.

Weaver, J.C. \& Morse, D.E. (2003). Molecular biology of demosponge axial filaments and their roles in biosilicification, Micro. Res. Tech., 62, 356-367.

Yang, H.; Coombs, N. \& Ozin, G.A. (1997). Morphogenesis of shapes and surface patterns in mesoporous silica, Nature, 386, 692-695.

Yang, S.H.; Park, J.H.; Cho, W.K.; Lee, H.-S. \& Choi, I.S. (2009). Counteranion-directed, biomimetic control of silica nanostructures on surfaces inspired by biosilicification found in diatoms, Smal, 5, 1947-1951.

Yuan, J.J. \& Jin, R.H. (2005a). Fibrous crystalline hydrogels formed from polymers possessing a linear poly(ethyleneimine) backbone, Langmuir, 21, 3136-3145.

Yuan, J.J. \& Jin, R.H. (2005b). Multiply shaped silica mediated by aggregates of linear poly(ethyleneimine), Adv. Mater., 17, 885-888.

Yuan, J.J.; Zhu, P.X.; Fukazawa, N. \& Jin, R.H. (2006). Synthesis of nanofiber-based silica networks mediated by organized poly(ethylene imine): structure, properties, and mechanism, Adv. Funct. Mater., 16, 2205-2212.

Yuan, J.J.; Mykhaylyk, O.O.; Ryan, A.J. \& Armes, S.P. (2007). Cross-linking of cationic block copolymer micelles by silica deposition, I Am. Chem. Soc., 129, 1717-1723.

Yuan, J.J. \& Jin, R.H. (2010a). Bioinspired synthesis of continuous titania coat with tunable nanofiber-based network structure on linear polyethyleneimine-covered substrates, Langmuir, 26, 4212-4218.

Yuan, J.J. \& Jin, R.H. (2010b). Water motion and movement without sticking, weight loss and cross-contaminant in superhydrophobic glass tube, Nanotechnology, 21, 065704.

Zhu, P.X. \& Jin, R.H. (2007). Polyethyleneimine aggregates regulated by metal cations acting as biomimetic organic reactors for silica architectures, Small, 3, 394-398.

Zhu, P.X. \& Jin, R.H. (2008). Environmentally benign and cost-effective silicification: From water glass to nanostructured silica by poly(ethyleneimine) mediation, cI Mater. Chem., 18, 313-318.

Zhu, P.X. \& Jin, R.H. (2010). Simple and efficient aqueous process for nanostructured fibrous $\mathrm{TiO} 2$ regulated by linear polyethyleneimine aggregates, Eur. II Inorg. Chem., 3, 476482.

Xiang, T.; Zhao, L.; Li, Y.; Lei, Z.; Jin, S.; Li, S.; Li, Y. \& Liang, Y. (2008). Template formation of aluminum-magnesium hydroxide nano-branches on linear poly(ethylene imine), Mater. Lett., 62, 1627-1629. 


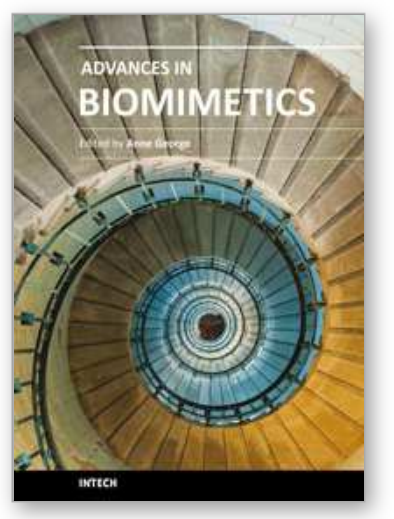

\author{
Advances in Biomimetics \\ Edited by Prof. Marko Cavrak
}

ISBN 978-953-307-191-6

Hard cover, 522 pages

Publisher InTech

Published online 26, April, 2011

Published in print edition April, 2011

The interaction between cells, tissues and biomaterial surfaces are the highlights of the book "Advances in Biomimetics". In this regard the effect of nanostructures and nanotopographies and their effect on the development of a new generation of biomaterials including advanced multifunctional scaffolds for tissue engineering are discussed. The 2 volumes contain articles that cover a wide spectrum of subject matter such as different aspects of the development of scaffolds and coatings with enhanced performance and bioactivity, including investigations of material surface-cell interactions.

\title{
How to reference
}

In order to correctly reference this scholarly work, feel free to copy and paste the following:

Ren-Hua Jin and Jian-Jun Yuan (2011). Learning from Biosilica: Nanostructured Silicas and Their Coatings on Substrates by Programmable Approaches, Advances in Biomimetics, Prof. Marko Cavrak (Ed.), ISBN: 978953-307-191-6, InTech, Available from: http://www.intechopen.com/books/advances-in-biomimetics/learningfrom-biosilica-nanostructured-silicas-and-their-coatings-on-substrates-by-programmable-appr

\section{INTECH}

open science | open minds

\section{InTech Europe}

University Campus STeP Ri

Slavka Krautzeka 83/A

51000 Rijeka, Croatia

Phone: +385 (51) 770447

Fax: +385 (51) 686166

www.intechopen.com

\section{InTech China}

Unit 405, Office Block, Hotel Equatorial Shanghai

No.65, Yan An Road (West), Shanghai, 200040, China

中国上海市延安西路65号上海国际贵都大饭店办公楼 405 单元

Phone: +86-21-62489820

Fax: +86-21-62489821 
(C) 2011 The Author(s). Licensee IntechOpen. This chapter is distributed under the terms of the Creative Commons Attribution-NonCommercialShareAlike-3.0 License, which permits use, distribution and reproduction for non-commercial purposes, provided the original is properly cited and derivative works building on this content are distributed under the same license. 